\title{
Fenofibrate Protects Cardiomyocytes from Hypoxia/Reperfusion- and High Glucose-Induced Detrimental Effects
}

\author{
Fabiola Cortes-Lopez, ${ }^{1}$ Alicia Sanchez-Mendoza ${ }^{(D)}{ }^{2}$ David Centurion $\left({ }^{1}{ }^{1}\right.$ \\ Luz G. Cervantes-Perez $\mathbb{D}^{\circ},{ }^{2}$ Vicente Castrejon-Tellez $\mathbb{i},{ }^{3}$ Leonardo del Valle-Mondragon $\left(\mathbb{D},{ }^{2}\right.$ \\ Elizabeth Soria-Castro $\mathbb{D},{ }^{4}$ Victoria Ramirez $\mathbb{D}{ }^{5}$ Araceli Sanchez-Lopez $\mathbb{D}$, \\ Gustavo Pastelin-Hernandez, ${ }^{2}$ Wylly Ramses Garcia-Niño $\left(\mathbb{D},{ }^{4}\right.$ Maria Sanchez-Aguilar $\left(\mathbb{D},{ }^{2}\right.$ \\ and Luz Ibarra-Lara $\mathbb{D D}^{2}$ \\ ${ }^{1}$ Department of Pharmacobiology, Center for Research and Advanced Studies of the National Polytechnic Institute, Calz. de los \\ Tenorios 235, Col Granjas Coapa, Tlalpan, 14330 Mexico City, Mexico \\ ${ }^{2}$ Department of Pharmacology, National Institute of Cardiology Ignacio Chávez, Juan Badiano No. 1, Col. Sección XVI, Tlalpan, \\ 14080 Mexico City, Mexico \\ ${ }^{3}$ Department of Physiology, National Institute of Cardiology Ignacio Chávez, Mexico City, Mexico \\ ${ }^{4}$ Department of Cardiovascular Biomedicine, National Institute of Cardiology Ignacio Chávez, Mexico City, Mexico \\ ${ }^{5}$ Department of Experimental Surgery, National Institute of Medical Sciences and Nutrition Salvador Zubirán, Vasco de Quiroga 15, \\ Belisario Domínguez, Col. Sección XVI, Tlalpan, 14080 Mexico City, Mexico
}

Correspondence should be addressed to Luz Ibarra-Lara; luzibarralara@yahoo.com.mx

Received 6 August 2020; Revised 3 December 2020; Accepted 22 December 2020; Published 9 January 2021

Academic Editor: Antonio Brunetti

Copyright (C) 2021 Fabiola Cortes-Lopez et al. This is an open access article distributed under the Creative Commons Attribution License, which permits unrestricted use, distribution, and reproduction in any medium, provided the original work is properly cited.

Lesions caused by high glucose (HG), hypoxia/reperfusion (H/R), and the coexistence of both conditions in cardiomyocytes are linked to an overproduction of reactive oxygen species (ROS), causing irreversible damage to macromolecules in the cardiomyocyte as well as its ultrastructure. Fenofibrate, a peroxisome proliferator-activated receptor alpha (PPAR $\alpha)$ agonist, promotes beneficial activities counteracting cardiac injury. Therefore, the objective of this work was to determine the potential protective effect of fenofibrate in cardiomyocytes exposed to $\mathrm{HG}, \mathrm{H} / \mathrm{R}$, and $\mathrm{HG}+\mathrm{H} / \mathrm{R}$. Cardiomyocyte cultures were divided into four main groups: (1) control (CT), (2) HG (25 mM), (3) H/R, and (4) HG+H/R. Our results indicate that cell viability decreases in cardiomyocytes undergoing $\mathrm{HG}, \mathrm{H} / \mathrm{R}$, and both conditions, while fenofibrate improves cell viability in every case. Fenofibrate also decreases ROS production as well as nicotinamide adenine dinucleotide phosphate oxidase (NADPH) subunit expression. Regarding the antioxidant defense, superoxide dismutase (SOD $\mathrm{Cu}^{2+} / \mathrm{Zn}^{2+}$ and SOD $\mathrm{Mn}^{2+}$ ), catalase, and the antioxidant capacity were decreased in $\mathrm{HG}, \mathrm{H} / \mathrm{R}$, and $\mathrm{HG}+\mathrm{H} / \mathrm{R}$-exposed cardiomyocytes, while fenofibrate increased those parameters. The expression of nuclear factor erythroid 2-related factor 2 (Nrf2) increased significantly in treated cells, while pathologies increased the expression of its inhibitor Keap1. Oxidative stress-induced mitochondrial damage was lower in fenofibrateexposed cardiomyocytes. Endothelial nitric oxide synthase was also favored in cardiomyocytes treated with fenofibrate. Our results suggest that fenofibrate preserves the antioxidant status and the ultrastructure in cardiomyocytes undergoing $\mathrm{HG}, \mathrm{H} / \mathrm{R}$, and $\mathrm{HG}+\mathrm{H} / \mathrm{R}$ preventing damage to essential macromolecules involved in the proper functioning of the cardiomyocyte.

\section{Introduction}

Diabetes is becoming alarmingly prevalent, raising the cardiovascular risk to develop myocardial ischemia and chronic heart failure with poor prognosis and survival [1]. The impaired glucose metabolism and the exacerbation of ischemia-reperfusion injury in diabetic myocardium enhances the production of oxygen reactive species (ROS), 
giving rise to oxidative stress and leading to biochemical and structural changes in detriment of cardiac function $[2,3]$.

Hyperglycemia and hypoxia-induced overproduction of anion superoxide damages organelles and macromolecules important for cell survival like lipids, enzymes, proteins, and DNA [4]. A key participant in this process is the activation of various NADPH oxidase isoforms in cardiovascular cells $[5,6]$. In this regard, the overproduction of ROS has been widely reported to promote the uncoupling of eNOS dimer; further increasing superoxide anion production [7]. Additionally, the presence of hypoxia-inducible factor-1 (HIF-1 $\alpha)$ is increased in response to hypoxia, in order to regulate a plethora of genes that help cells to cope with oxygen restriction [8]. In order to decrease ROS production, it is necessary to activate and/or increase the antioxidant defense or to diminish oxidative stress [9]. Therefore, novel therapeutic strategies are required to protect the myocardium against the effects of ischemia-reperfusion (I/R) injury in hyperglycemic conditions.

A pharmacological target to counteract oxidative stressinduced damage may be peroxisome proliferator-activated receptors (PPARs) which are nuclear proteins acting as transcription factors $[10,11]$. Besides a role in lipid metabolism PPARs play a number of pleiotropic effects, that include a critical role in myocardial health, and influence the production of cytokines and growth factor release, leading to antiinflammatory and anti -proliferative effects [12]. The three main types of PPARs are encoded by separate genes and their products have been identified as $\operatorname{PPAR}$ alpha $(\operatorname{PPAR} \alpha)$, PPAR gamma $(\operatorname{PPAR} \gamma)$, and PPAR beta/delta $(\operatorname{PPAR} \beta / \delta)$ [13]. The activation of $\operatorname{PPAR} \alpha$ mediates effects such as the catabolism of fatty acids through the stimulation of mitochondrial lipid oxidation [14]. In previous works $[15,16]$ we have shown that, in vivo activation of PPAR $\alpha$ modulates the cardiac production of ROS, as well as the expression of antioxidant enzymes. Fenofibrate, a PPAR $\alpha$ agonist, has been clinically used for more than 30 years to reduce triglycerides and cholesterol levels in patients at risk of cardiovascular disease and has shown successful protection against the deleterious effects of $\mathrm{I} / \mathrm{R}$ in experimental settings [17, 18]. Remarkably, fenofibrate possesses $\operatorname{PPAR} \alpha$-mediated antiinflammatory, antioxidant and antifibrotic effects that may account for its direct cardioprotective $[10,11]$. In addition, fenofibrate supports cardiac function and improves postischemic functional recovery in diet-induced obese mice [19]. Alternatively, fenofibrate therapy prevents isoproterenolinduced myocardial infarction [20] but also, inhibits the reperfusion-induced cardiac arrhythmias in isolated rat hearts [21].

However, up to date, no study has analysed the effect of fenofibrate in cultured cardiomyocytes undergoing $\mathrm{H} / \mathrm{R}, \mathrm{HG}$ and the combination of these conditions (HG+ $\mathrm{H} / \mathrm{R})$. This latter could allow us to reproduce in vivo observed features and could be an in vitro model for further studies. Therefore, the aim of the study is to characterize the effects of fenofibrate treatment on oxidative stress and structural damage in cardiomyocytes subjected to hypoxia-reperfusion, high glucose and the combination of both conditions.

\section{Materials and Methods}

2.1. Animals. Newborn male and female Wistar rats (1-3 days), provided by the animal facilities of the Center for Research and Advanced Studies of the National Polytechnic Institute (CINVESTAV), were used to obtain cardiomyocytes. The protocol was carried out following the guidelines of the Institutional Ethics Committee (protocol number 0270/18), as well as those of the Official Mexican Standard for the use and care of laboratory animals NOM-062-ZOO 1999.

\subsection{Neonatal Rat Cardiomyocyte (NRCM) Isolation and} Culture. As previously described [22], NRCMs were isolated from the heart of 1- to 3-day-old Wistar rats. Extirpated hearts were minced, and ventricles were digested four times for fifteen minutes each in trypsin (0.25\% Invitrogen, Carlsbad, CA, USA) in a sterile environment. Cells were incubated for 90 minutes in cell culture flasks to allow noncardiac myocytes (mainly cardiac fibroblasts) to adhere to the plastic. NRCMs were cultured in F-10 medium (1x) nutrient mixture (HAM) with L-glutamine (Gibco, Waltham, MA, USA) containing $5.5 \mathrm{mmol} / \mathrm{L}$ of D-glucose supplemented with $10 \%$ heat-inactivated fetal bovine serum (FBS, Invitrogen, Carlsbad, CA, USA), $100 \mathrm{U} / \mathrm{mL}$ of penicillin, and $100 \mathrm{mg} / \mathrm{L}$ of streptomycin (Gibco, Waltham, MA, USA). NRCMs $\left(1 \times 10^{6}\right.$ cells $)$ were placed in a six-well culture plate and incubated at $37^{\circ} \mathrm{C}$ in a humidified atmosphere $(5 \%$ $\mathrm{CO}_{2} / 95 \% \mathrm{O}_{2}$ ). Experiments were performed on beating and confluent monolayers on the 3rd to 5 th day of culture. Cell cultures were subdivided into the following experimental groups: (1) control treated with vehicle DMSO (0.1\%) (control-DMSO), (2) control treated with fenofibrate $(10 \mu \mathrm{M})$ (control-Feno), (3) control treated with mannitol (19.5 mM) (control-mannitol), (4) hypoxia/reperfusion treated with DMSO (0.1\%) (H/R-DMSO), (5) H/R treated with fenofibrate $(10 \mu \mathrm{M})$ (H/R-Feno), (6) high glucose (25 mM) treated with DMSO (0.1\%) (HG-DMSO), (7) high glucose $(25 \mathrm{mM})$ treated with fenofibrate $(10 \mu \mathrm{M})$ (HGFeno), (8) high glucose $(25 \mathrm{mM})$ plus hypoxia/reperfusion treated with DMSO (0.1\%) (HG+H/R-DMSO), and (9) high glucose $25 \mathrm{mM}$ plus hypoxia/reperfusion treated with fenofibrate $(10 \mu \mathrm{M})(\mathrm{HG}+\mathrm{H} / \mathrm{R}-\mathrm{Feno})$ (Figure 1). High glucose was produced by incubating cells for 48 hours in F-10 medium containing $25 \mathrm{mmol} / \mathrm{L}$ of glucose $((+) D$-glucose at $200 \mathrm{~g} / \mathrm{L}$, Gibco, Waltham, MA, USA). To produce H/R, cell cultures were covered with a coverslip for two hours [23, 24]. After that, the coverslip was removed and the cells were reoxygenated for 1 hour. Vehicle (DMSO, 0.1\%) or fenofibrate (10 $\mu \mathrm{M}$, purity $\geq 99 \%$, Sigma-Aldrich, St. Louis, MO, USA) were administered according to Figure 1.

In order to explore hyperosmolarity, cells were exposed to mannitol (19.5 mM, D-mannitol, Sigma-Aldrich, St. Louis, MO, USA).

2.3. Cell Viability. Cell viability was carried out according to Strober and Crowley et al. $[25,26]$. A volume of $0.1 \mathrm{~mL}$ of trypan blue $0.4 \%$ was added to $1 \mathrm{~mL}$ of cells $\left(1 \times 10^{6}\right.$ cells $)$. An aliquot of $50 \mu \mathrm{L}$ of cells was loaded on a Neubauer chamber 


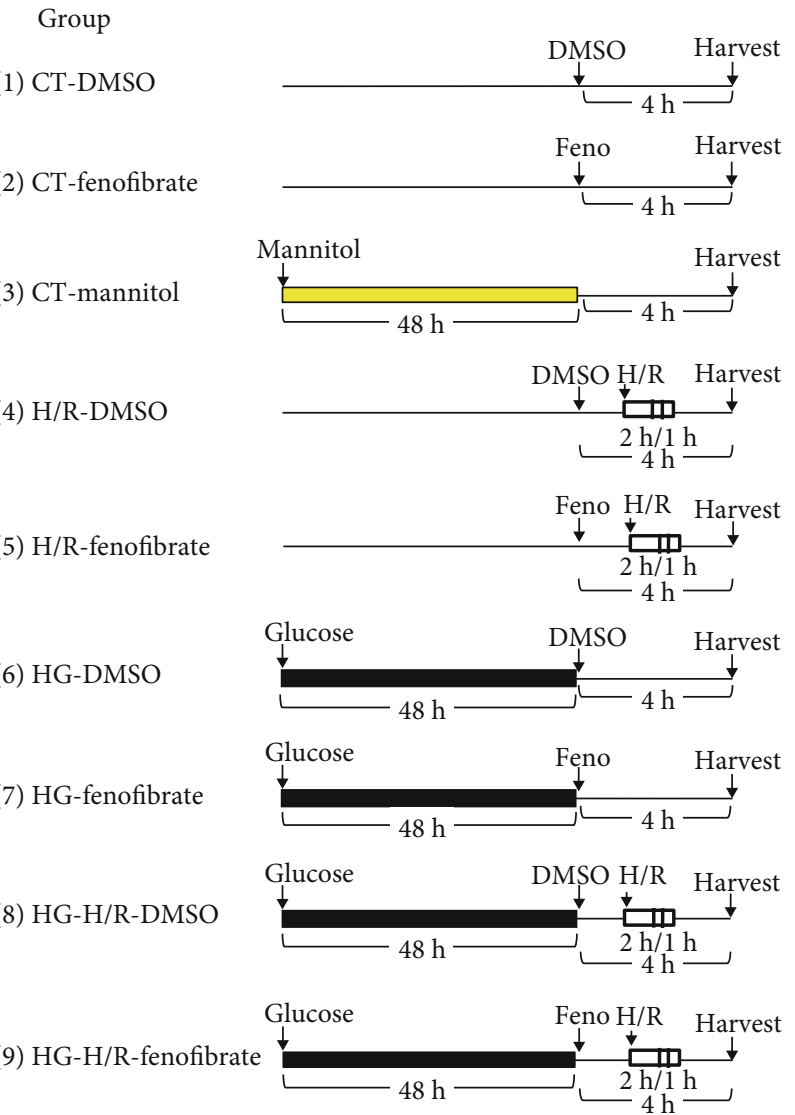

FIGURE 1: Schematic representation of the experimental group design. Primary cardiomyocyte cultures were divided into 9 groups. Mannitol $(19.5 \mathrm{mM})$ and high glucose $(25 \mathrm{mM})$ were administered $48 \mathrm{hrs}$ before fenofibrate $(10 \mu \mathrm{M})$ or DMSO $(0.1 \%)$ treatment. Exposition time for either fenofibrate or DMSO treatment was $4 \mathrm{hrs}$, with or without hypoxia-reperfusion maneuver, before harvest. $\mathrm{CT}=$ control; $\mathrm{H} / \mathrm{R}=$ hypoxiareperfusion; $\mathrm{HG}=$ high glucose; $\mathrm{DMSO}=$ dimethylsulfoxide $0.1 \%$; Feno $=$ fenofibrate $10 \mu \mathrm{M}$. Yellow bar represents mannitoltreatment period, black bar represents glucose-treatment period, white bar represents hypoxia period, and dashed bar represents reoxygenation period.

(Neubauer, Marienfeld, $0.0025 \mathrm{~mm}^{2}$; Wöllerspfad LaudaKönigshofen, Germany) and immediately examined under a microscope at 10x magnification. The amount of bluestained cells (dead) and the total number of cells were counted. The cell viability must be at least $95 \%$ to consider a healthy logarithmic phase culture.

2.4. Real-Time PCR. Using the TRIzol Reagent (Thermo Fisher Scientific, Rockford, IL, USA), RNA was isolated from the equivalent of $5 \times 10^{6}$ cells from the different experimental groups. The integrity of the RNA was checked on a $1 \%$ agarose gel. First, a reaction with reverse transcriptase (RT) with $2.5 \mu \mathrm{g}$ of total RNA in the presence of $200 \mathrm{U}$ of reverse transcriptase (RT) from the Moloney Murine Leukemia Virus (MMLV) (Invitrogen, USA) was carried on. The amount of HIF- $1 \alpha$ mRNA was quantified by real-time PCR in the ABI Prism 7000 Sequence Detection System (TaqMan, ABI, Fos- ter City, CA, USA) through the reaction with SYBR Green. As an endogenous control, GAPDH was used and the sequences of the HIF- $1 \alpha$ harvesters used were the following: ATACCAGCAGTAACCAGCCG (sense) and CTGTGG CTGAGAGTCCTTCG (antisense). The method to calculate the amount of HIF- $1 \alpha$ was $\Delta \mathrm{CT}$ (increase of the cycle threshold) [27].

2.5. ROS Production. Cardiomyocytes $\left(1 \times 10^{6}\right)$ from the different experimental groups were washed with PBS and incubated for $30 \mathrm{~min}$ in the darkness with the CellRox ${ }^{\mathrm{TM}}$ Green Reagent (Thermo Fisher Scientific, Waltham, MA, USA) at a final concentration of $5 \mu \mathrm{M}$. After incubation, the medium was removed, the cells were washed twice with PBS, scraped off with $1 \mathrm{~mL}$ of PBS, and placed in dark Eppendorf tubes. Subsequently, the fluorescence emitted by the interaction of the free radicals with the CellRox indicator was determined by a flow cytometer (FACSCalibur model, BD Biosciences, San Jose, CA, USA) and the CellQuest analysis program (BD Biosciences, San Diego, CA, USA). The results were calculated as the geometric mean fluorescence (MF) in FL1 of 3000 events, obtained by region and its fluorescence histograms, where the displacement of the fluorescence peaks is observed depending on the treatment in each cell group loaded with the CellRox indicator, all of them compared with the intrinsic fluorescence of a group of cells that were incubated without the indicator $[28,29]$.

2.6. Protein Expression by Western blot. Total protein content in the cultures was quantified by the BCA Protein Assay Kit (Pierce, Waltham, MA, USA) as previously reported [30]. Protein from cell lysates ( $80 \mu \mathrm{g}$ of protein) were subjected to separation on a $12 \%$ SDS-PAGE gel $(100 \mathrm{~V})$ for 2 hours, followed by electrotransfer to a polyvinylidene fluoride (PVDF) membrane $(0.45 \mu \mathrm{m}$, Millipore, Billerica, MA, USA) at $10 \mathrm{~V}$ for 1 hour. In order to block unspecific binding, membranes were incubated with 5\% nonfat milk (Bio-Rad, Hercules, CA, USA) in PBS-Tween $0.1 \%$ as reported elsewhere. Blots were probed with specific antibodies against $\beta$ actin $(1: 5000)$, HIF- $1 \alpha(1: 100)$, SOD $\mathrm{Cu}^{2+} / \mathrm{Zn}^{2+}(1: 100)$, SOD $\mathrm{Mn}^{2+}(1: 100)$, p47phox $(1: 100)$, NOX4 (1:100), eNOS $(1: 100)$, p-eNOS $^{\mathrm{Ser}} 1177 \quad(1: 100), \operatorname{PPAR} \alpha \quad(1: 50), \mathrm{Nrf} 2$ (1:50), Keap1 (1:50) (Santa Cruz Biotechnology Inc., Santa Cruz, CA, USA), and p-PPAR $\alpha^{\text {Ser12 }}$ (Abcam, Cambridge, UK). Signals were detected by the Immobilon Western Chemiluminescent HRP Substrate (Millipore, Billerica, MA, USA). Images from each film were acquired by a GS-800 densitometer (including Quantity One software from Bio-Rad Laboratories, Inc., Hercules, CA, USA). Blots were stripped and reincubated with $\beta$-actin antibody as load control. Values of each band density are expressed as arbitrary units.

2.7. Antioxidant Capacity Assay. Total antioxidant capacity was determined by the method described by Apak et al. [31]. Briefly, a suspension of $6 \times 10^{6}$ cells previously centrifuged $1500 \mathrm{rpm} / 10 \mathrm{~min}$ was diluted with $145 \mu \mathrm{L}$ of $0.1 \mathrm{M}$ phosphate buffer at $\mathrm{pH} 7.5$ and shook at $500 \mathrm{rpm}$ for $200 \mathrm{sec} .100 \mu \mathrm{L}$ of the diluted sample was further treated with $50 \mu \mathrm{L}$ of $0.01 \mathrm{M} \mathrm{CuCl}_{2}$ and shook at $500 \mathrm{rpm}$ for $200 \mathrm{sec}$. 
Then, $50 \mu \mathrm{L}$ of $0.01 \mathrm{M}$ batocuproin was added and vortexed again at $500 \mathrm{rpm}$ for $200 \mathrm{sec}$. The concentration of $\mathrm{Cu}^{2+}$ reduced to $\mathrm{Cu}^{+}$was measured by means of a spectrometer to $490 \mathrm{~nm}$ (DW2000, SLM-Aminco, Urbana, IL, USA). Total antioxidant capacity is expressed as $\mu \mathrm{mol} / \mathrm{L}$ of $\mathrm{Cu}^{2+}$ reduced to $\mathrm{Cu}^{+}$and is calculated as follows:

$$
\mathrm{TAC}=\left(\Delta F_{\mathrm{em}}\right)(\mathrm{DF})(6.418629 \mu \mathrm{mol} / \mathrm{L}),
$$

where TAC is the total antioxidant capacity, $\Delta F_{\mathrm{em}}$ is the flourescence difference emitted (treated sample-diluted sample), $\mathrm{DF}$ is the dilution factor ( $\mathrm{DF}=8$ ), and the kinetics factor of extinction-emission for the $\mathrm{Cu}^{2+}$ batocuproin complex is $641.8629 \mu \mathrm{mol} / \mathrm{L}$.

2.8. Quantification of Malondialdehyde. Malondialdehyde (MDA) was determined by capillary zone electrophoresis in cardiomyocytes $\left(6 \times 10^{6}\right.$ cells $)$ obtained from every experimental group, as described by Sánchez-Aguilar et al. [30]. The sample was deproteinized with cold methanol $(1: 1)$, centrifuged at $16,000 \times g$ for 15 minutes, and filtered through a $0.22 \mu \mathrm{m}$ nitrocellulose membrane filter (Millipore, Billerica, MA, USA). It was diluted $(1: 10)$ with cold sodium hydroxide $(0.1 \mathrm{M})$ and analyzed in a P/ACE ${ }^{\mathrm{TM}}$ MDQ Capillary Electrophoresis System (Beckman Coulter, California, USA) under the following conditions: The samples were injected under hydrodynamic pressure at $0.5 \mathrm{psi} / 10 \mathrm{~s}$. The separation was performed at $-25 \mathrm{kV}$ for $4 \mathrm{~min}$ at $267 \mathrm{~nm}$. The capillary was washed between runs with $0.1 \mathrm{M} \mathrm{NaOH}$ for 2 minutes, distilled water for $2 \mathrm{~min}$, and phosphate buffer for 4 minutes. The concentration of MDA was expressed in $\mu \mathrm{M}$ and was determined interpolating with a standard curve.

2.9. Quantification of 8-Hydroxy-2'-Deoxyguanosine. 8Hydroxy- $2^{\prime}$-deoxyguanosine $(8-\mathrm{OH}-2 \mathrm{dG})$ was determined by capillary zone electrophoresis and UV detection, by diode array as described by Sánchez-Aguilar et al. [30]. A sample of cardiomyocytes $\left(6 \times 10^{6}\right.$ cells $)$ from each experimental group was deproteinized with $20 \%$ trichloroacetic acid $(10: 1)$. It was centrifuged at $16,000 \times g$ for 15 minutes and filtered through $0.22 \mu \mathrm{m}$ nitrocellulose membrane filters. Samples were analyzed with the P/ACE ${ }^{\mathrm{TM}} \mathrm{MDQ}$ Capillary Electrophoresis System (Beckman Coulter, CA, USA). The capillary was preconditioned passing a solution of $2 \mathrm{M}$ sodium hydroxide for $30 \mathrm{~min}$, then deionized water for $30 \mathrm{~min}$, and finally running buffer ( $10 \mathrm{mM}$ borates, $\mathrm{pH} 9.0)$ for $30 \mathrm{~min}$. The sample was injected under hydrodynamic pressure at $0.5 \mathrm{psi} / 10 \mathrm{~s}$. The separation was carried out at $20 \mathrm{kV}$ for $8 \mathrm{~min}$ at $200 \mathrm{~nm}$. The capillary was washed between runs with $2 \mathrm{M}$ $\mathrm{NaOH}$ for $2 \mathrm{~min}$ and distilled water for $2 \mathrm{~min}$. The results were expressed in $\mathrm{pmol} / \mathrm{mL}$. The concentration of $8-\mathrm{OH}-$ $2 \mathrm{dG}$ was determined interpolating the values with a standard curve.

2.10. Capillary Zone Electrophoresis for Determination of $\mathrm{BH}_{4}$ and $\mathrm{BH}_{2}$. The contents of $\mathrm{BH}_{4}$ and $\mathrm{BH}_{2}$ in cardiomyocytes from every experimental group were determined as described by Ibarra-Lara et al. [16]. Briefly, $50 \mu \mathrm{L}$ of sample containing $6 \times 10^{6}$ cells was deproteinized with cold methanol $(1: 1 \mathrm{v} / \mathrm{v})$ and centrifuged at $16,000 \times g$ for $15 \mathrm{~min}$ at $10^{\circ} \mathrm{C}$ and filtered with a nitrocellulose membrane $(0.22 \mu \mathrm{m}$, Millipore, Billerica, MA, USA). Measurement was performed using a $\mathrm{P} / \mathrm{ACE}^{\mathrm{TM}} \mathrm{MDQ}$ Capillary Electrophoresis System (Beckman Coulter, Mexico City, Mexico), with laser-induced fluorescence detection. A standard curve of $\mathrm{BH}_{2}$ and $\mathrm{BH}_{4}$ (SigmaAldrich, St. Louis, MO, USA) was used to calculate concentrations. Data are expressed as $\mathrm{pmol} / \mathrm{mg}$ of protein of $\mathrm{BH}_{4}$ and $\mathrm{BH}_{2}$.

2.11. Electron Microscopy. Electron microscopy was used to evaluate the ultrastructure of cardiomyocytes. We followed the method described by Ibarra-Lara et al. [16] using $1 \times$ $10^{6}$ cells. The evaluation was carried out with a JEM 1011 (JEOL Ltd., Tokyo, Japan) at $60 \mathrm{kV}$. The magnification employed was 50,000x.

2.12. Data Analysis. Data obtained is presented as the mean \pm standard error of the mean of 6 independent experiments. Differences between the groups were analyzed by two-way analysis of variance (two-way ANOVA) followed by Tukey's post hoc test. Statistical significance was accepted when $p<$ 0.05 . For comparisons between two groups, an unpaired Student's $t$-test was used.

\section{Results}

3.1. HIF-1 $\alpha$ Evaluation. To determine if the method used to induce hypoxia (coverslip) was effective, we determined the expression of HIF- $1 \alpha$. This determination was carried out through qPCR and Western blot. Our results show that both mRNA and protein HIF- $1 \alpha$ were significantly increased in cultures undergoing hypoxia-reperfusion compared to control (Figures 2(a) and 2(b)). These results suggest that the method employed to generate hypoxia (coverslip) was effective.

3.2. Evaluation of Cell Viability. To determine cell viability, we used the trypan blue dye technique. Accordingly, our results indicate that cardiomyocytes under DMSO, fenofibrate, or mannitol exhibited cell viability above 95\%, indicating that cell cultures were in optimal conditions and that treatments exerted no harm. On the other hand, cardiomyocytes exposed to $\mathrm{H} / \mathrm{R}, \mathrm{HG}$, and $\mathrm{HG}+\mathrm{H} / \mathrm{R}$ exhibited lower cell viability compared to the control groups. Fenofibrate administration in the H/R group was able to prevent cell death. In addition, we observed that HG cells exposed to fenofibrate exhibited a viability comparable to those HG-DMSOexposed cardiomyocytes (Figure 3), a result that suggests a lack of fenofibrate-induced effect once the hyperglycemiainduced damage is done. It is worth mentioning that mannitol did not induce loss of cell viability, ruling out hyperosmolarity as the responsible process for cell death and confirming the harmful effect of high glucose per se. The fenofibrate effect can be observed in the group with both conditions where it increased cell viability; this result was different from the $\mathrm{HG}+\mathrm{H} / \mathrm{R}-\mathrm{DMSO}$ group, suggesting that fenofibrate could be helpful to preserve cell viability after H/R although high glucose is present. 


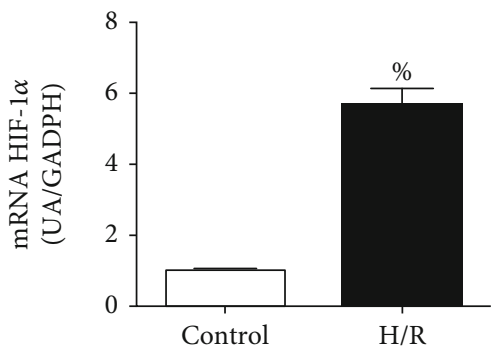

(a)

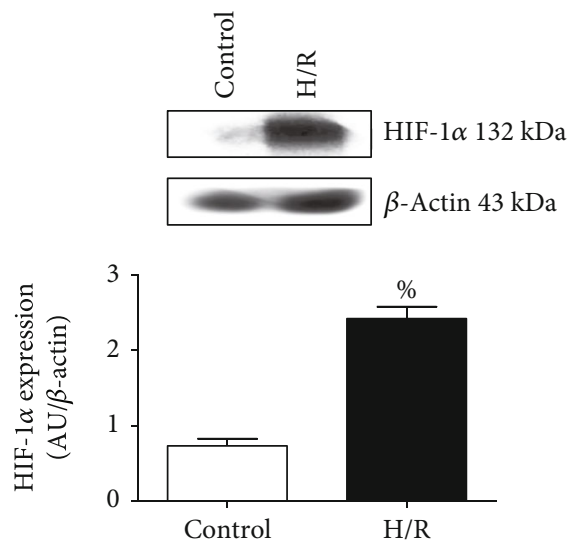

(b)

FIGURE 2: Evaluation of the efficiency of the coverslip assay by quantification of HIF- $1 \alpha$ in primary cultures of cardiomyocytes undergoing hypoxia/reperfusion (H/R). (a) Quantification of mRNA HIF- $1 \alpha$ performed through qPCR. HIF-1 $\alpha$ sense: ATACCAGCAGTAACCA GCCG; antisense: CTGTGGCTGAGAGTCCTTCG. (b) Protein expression of HIF-1 $\alpha$ by Western blot and quantified by densitometric analysis. The values represent the mean \pm standard error of the mean (SEM) of 5 different experiments. ${ }^{\%} p<0.05$ vs. control. Student's unpaired $t$-test.

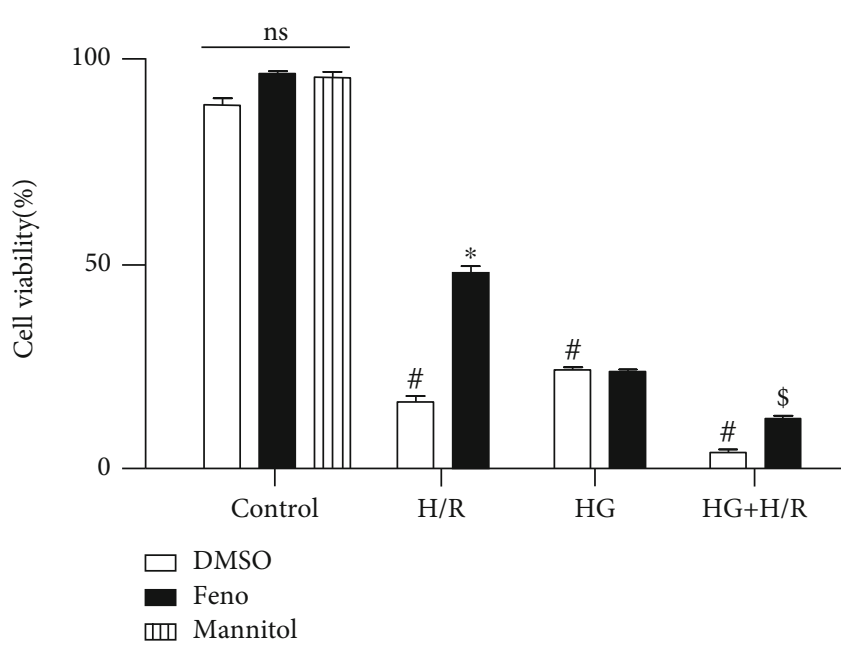

FIGURE 3: Effect of fenofibrate $(10 \mu \mathrm{M})$ on cell viability. Cell viability was assessed by a trypan blue dye exclusion test of control, hypoxia/reperfusion (H/R), high glucose (HG), or the combination of conditions $(\mathrm{HG}+\mathrm{H} / \mathrm{R})$ in primary culture of cardiomyocytes. DMSO = dimethylsulfoxide (0.1\%); Feno = fenofibrate $(10 \mu \mathrm{M}) .{ }^{*} p<0.05$ vs. control-DMSO; ${ }^{*} p<0.05$ vs. H/R-DMSO; ${ }^{\$} p<0.05$ vs. HG+H/R-DMSO. Values represent the mean \pm SEM of 6 different experiments. Two-way analysis of variance (ANOVA) followed by Tukey's post hoc test.

3.3. Production of ROS. As shown in Figure 4, the effect of fenofibrate on ROS production was determined in $\mathrm{H} / \mathrm{R}$, $\mathrm{HG}$, and $\mathrm{HG}+\mathrm{H} / \mathrm{R}$ conditions. Our results show that the $\mathrm{H} / \mathrm{R}, \mathrm{HG}$, and the coexistence of both conditions significantly increased ROS production. Fenofibrate treatment decreased ROS production despite the presence of pathological conditions (Figures 4(a) $-4(\mathrm{c})$ ).

3.4. Evaluation of the Antioxidant Effect. To explore the role of PPAR $\alpha$ in antioxidant defense, the expression of SOD
$\mathrm{Cu}^{2+} / \mathrm{Zn}^{2+}$, SOD $\mathrm{Mn}^{2+}$, and catalase was measured in the different groups. The results obtained show that the expression of antioxidant enzymes decreased in the HG, $\mathrm{H} / \mathrm{R}$, and $\mathrm{HG}+$ $\mathrm{H} / \mathrm{R}$ groups. Interestingly, treatment with fenofibrate significantly increased the expression of SODs and catalase (Figures 5(a)-5(c)). These results suggest that the activation of PPAR $\alpha$ by fenofibrate decreased oxidative stress due to the increased expression of antioxidant enzymes. In order to investigate further the antioxidant mechanism of fenofibrate, the expression of the Keap1/Nrf2 pathway was determined. Our results indicate that cardiomyocytes, under pathological conditions (HG, $\mathrm{H} / \mathrm{R}$, and $\mathrm{HG}+\mathrm{H} / \mathrm{R}$ ), exhibited a lower expression of Nrf2, while fenofibrate increased its expression (Figure 5(d)). Fenofibrate treatment decreased Keap1 expression (Figure 5(e)). As expected, treatment with fenofibrate increased the total antioxidant capacity in HG, $\mathrm{H} / \mathrm{R}$, and $\mathrm{HG}+\mathrm{H} / \mathrm{R}$ (Figure 5(f)). Therefore, fenofibrate favors an antioxidant environment in cultured cardiomyocytes.

3.5. Evaluation of the Expression of NADPH Subunits. Due to the relevance of NADPH oxidase p47phox- and NOX4-subunits, we evaluated their expression. In control cardiomyocytes, we did not observe the expression of these proteins. Interestingly, in $\mathrm{H} / \mathrm{R}, \mathrm{HG}$, and $\mathrm{HG}+\mathrm{H} / \mathrm{R}$-exposed cardiomyocytes, the expression of both NADPH subunits significantly increased. Remarkably, this effect was prevented by fenofibrate (Figures 6(a) and 6(b)).

3.6. Effect of Fenofibrate on Malondialdehyde, 8-Hydroxy-2Desoxyguanosine, $\mathrm{BH}_{4}$, and $\mathrm{BH}_{2}$. Reactive oxygen species may interact with several targets in the cell. Likewise, lipids, DNA, and metabolites are oxidized by their action, modifying their physiological role. The lipid damage indicator, MDA, was found increased in the $\mathrm{H} / \mathrm{R}, \mathrm{HG}$, and $\mathrm{HG}+\mathrm{H} / \mathrm{R}$ groups, compared to control. In addition, MDA decreased significantly in every cardiomyocyte culture $(\mathrm{H} / \mathrm{R}, \mathrm{HG}$, and 

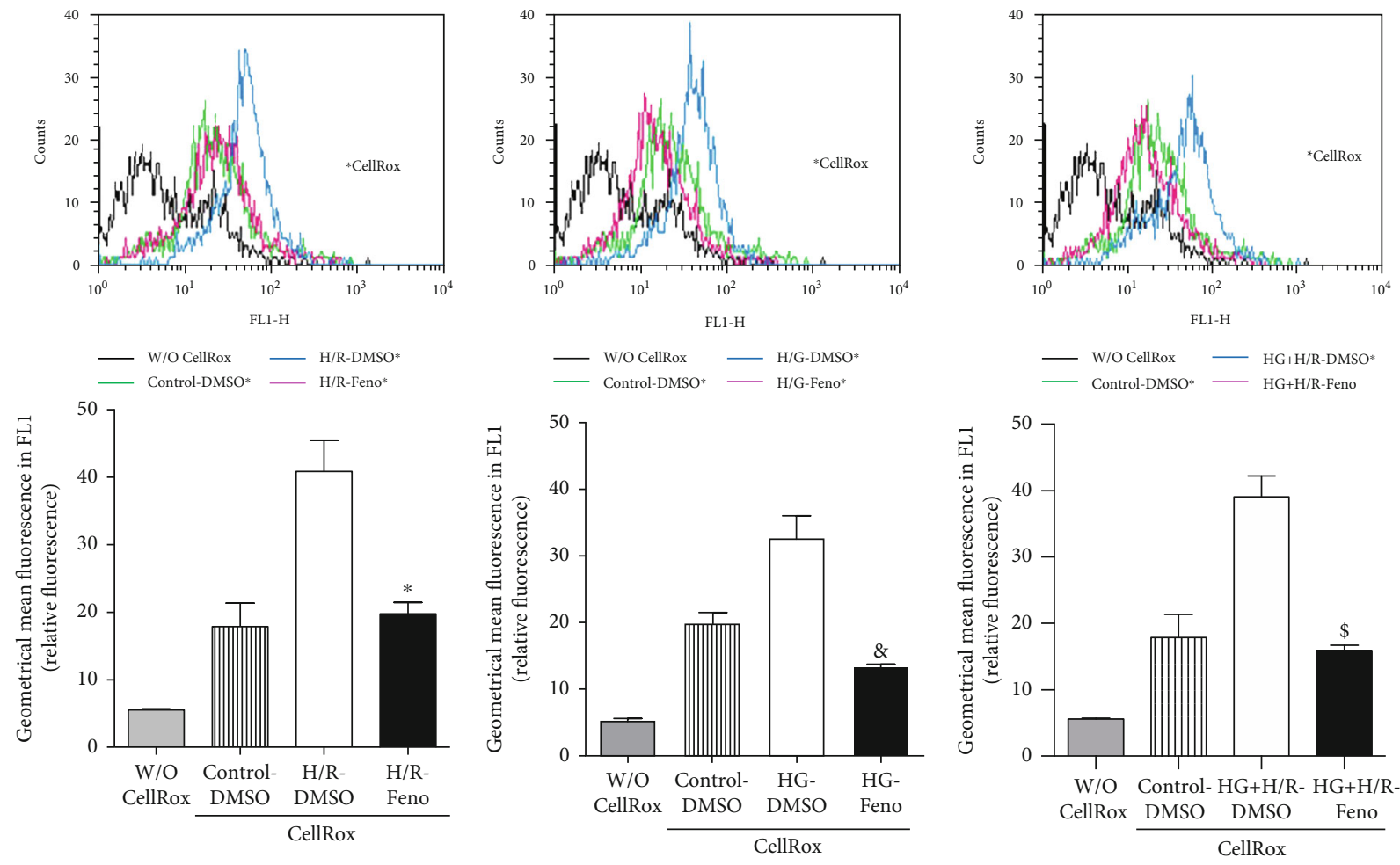

(a)

(b)

(c)

FIGURE 4: Electropherograms and quantification of ROS production by flow cytometry in primary cultures of cardiomyocytes under (a) hypoxia/reperfusion (H/R), (b) high glucose (HG), or (c) HG+H/R. ${ }^{*} p<0.05$ vs. H/R-DMSO; ${ }^{*} p<0.05$ vs. HG-DMSO; ${ }^{\$} p<0.05$ vs. HG+H/R-DMSO. W/O CellRox = blank; CellRox = vehicle; DMSO = dimethylsulfoxide (0.1\%); Feno = fenofibrate $(10 \mu \mathrm{M})$. Values represent the mean \pm SEM of 6 different experiments. Two-way analysis of variance (ANOVA) followed by Tukey's post hoc test.

$\mathrm{HG}+\mathrm{H} / \mathrm{R}$ ) incubated with fenofibrate (Figure $7(\mathrm{a})$ ). The effect on DNA was also evaluated through the presence of 8-hydroxy-2-desoxyguanosine (8-OH-2dG), an essential marker of oxidative damage on DNA. Our results indicate that this parameter increased in the $\mathrm{H} / \mathrm{R}, \mathrm{HG}$, and $\mathrm{HG}+$ $\mathrm{H} / \mathrm{R}$ groups. Interestingly, the stimulation of $\operatorname{PPAR} \alpha$ by fenofibrate significantly decreased the values of this DNA damage marker (Figure $7(\mathrm{~b})$ ). In order to produce nitric oxide (NO), endothelial nitric oxide synthase (eNOS) requires cofactors such as $\mathrm{BH}_{4}$. However, this molecule is highly susceptible to be oxidized to $\mathrm{BH}_{2}$, promoting an uncoupled state in eNOS being unable to synthesize NO and instead producing $\mathrm{O}_{2}{ }^{\bullet-}$. Therefore, the concentrations of $\mathrm{BH}_{4}$ and $\mathrm{BH}_{2}$ were determined by capillary zone electrophoresis. The results show that either $\mathrm{H} / \mathrm{R}, \mathrm{HG}$, or the coexistence of both experimental conditions induced a significant decrement of $\mathrm{BH}_{4}$ levels. In addition, treatment with fenofibrate prevented the oxidation of $\mathrm{BH}_{4}$ (Figure $7(\mathrm{c})$ ). On the other hand, $\mathrm{BH}_{2}$ levels increased in the $\mathrm{HG}$ and $\mathrm{HG}+\mathrm{H} / \mathrm{R}$ groups. Again, fenofibrate maintained this parameter at levels similar to the control group (Figure $7(\mathrm{~d})$ ). These results suggest that fenofibrate favors an eNOS-coupled state due to the lower oxidation of $\mathrm{BH}_{4}$ in a process in which oxidative stress is involved.

3.7. Evaluation of the Expression of eNOS and P-eNOS ${ }^{\text {Ser1177. }}$ Figure 8 shows the effect of fenofibrate on eNOS and $\mathrm{p}$ eNOS $^{\text {Ser1177 }}$ expression in the $\mathrm{HG}, \mathrm{H} / \mathrm{R}$, and $\mathrm{HG}+\mathrm{H} / \mathrm{R}$ groups. Our results show that eNOS expression is affected by $\mathrm{HG}, \mathrm{H} / \mathrm{R}$, and the combination of pathological factors at both nonphosphorylated (eNOS) and phosphorylated ( $\mathrm{p}$ eNOS $^{\mathrm{Ser1177}}$ ) forms exhibited as a reduction in their expression. As expected, fenofibrate treatment significantly increased the expression of eNOS and p-eNOS Ser1177 suggesting that the PPAR $\alpha$ activator potentially increases NObioavailability (Figures 8 (a) and 8(b)).

3.8. Evaluation of the Expression of PPAR $\alpha$ and $p-P P A R \alpha^{S e r 12}$. In order to probe that fenofibrate was able to stimulate $\operatorname{PPAR} \alpha$, we evaluated its expression as well as $\operatorname{p-PPAR} \alpha^{\mathrm{Ser} 12}$, a marker of fibrate action. As shown on Figure 9(a), the $H / R$, $\mathrm{HG}$, and $\mathrm{HG}+\mathrm{H} / \mathrm{R}$ groups have a downward trend of PPAR $\alpha$ expression. In Figure 9(b), we can observe a low profile of $\mathrm{p}$ PPAR $\alpha$ Ser12 expression in the $H / R, H G$, and $H G+H / R$ groups. However, fenofibrate significantly increased the expression of PPAR $\alpha$ and $\mathrm{p}-\operatorname{PPAR} \alpha^{\mathrm{Ser} 12}$, suggesting that fenofibrate was able to reach its target and activate it.

3.9. Evaluation of the Ultrastructure of Cardiomyocytes. It was observed that in the control and control-fenofibrate groups, there was an homogeneous distribution of mitochondria, as well as a continuous membrane (Figure 10(a)). Cardiomyocytes subjected to H/R exhibited tubular mitochondrial ridges and were less dense than controls. In addition, there was an emptying of its content and the membranes exhibited discontinuous borders. On the other hand, fenofibrate 

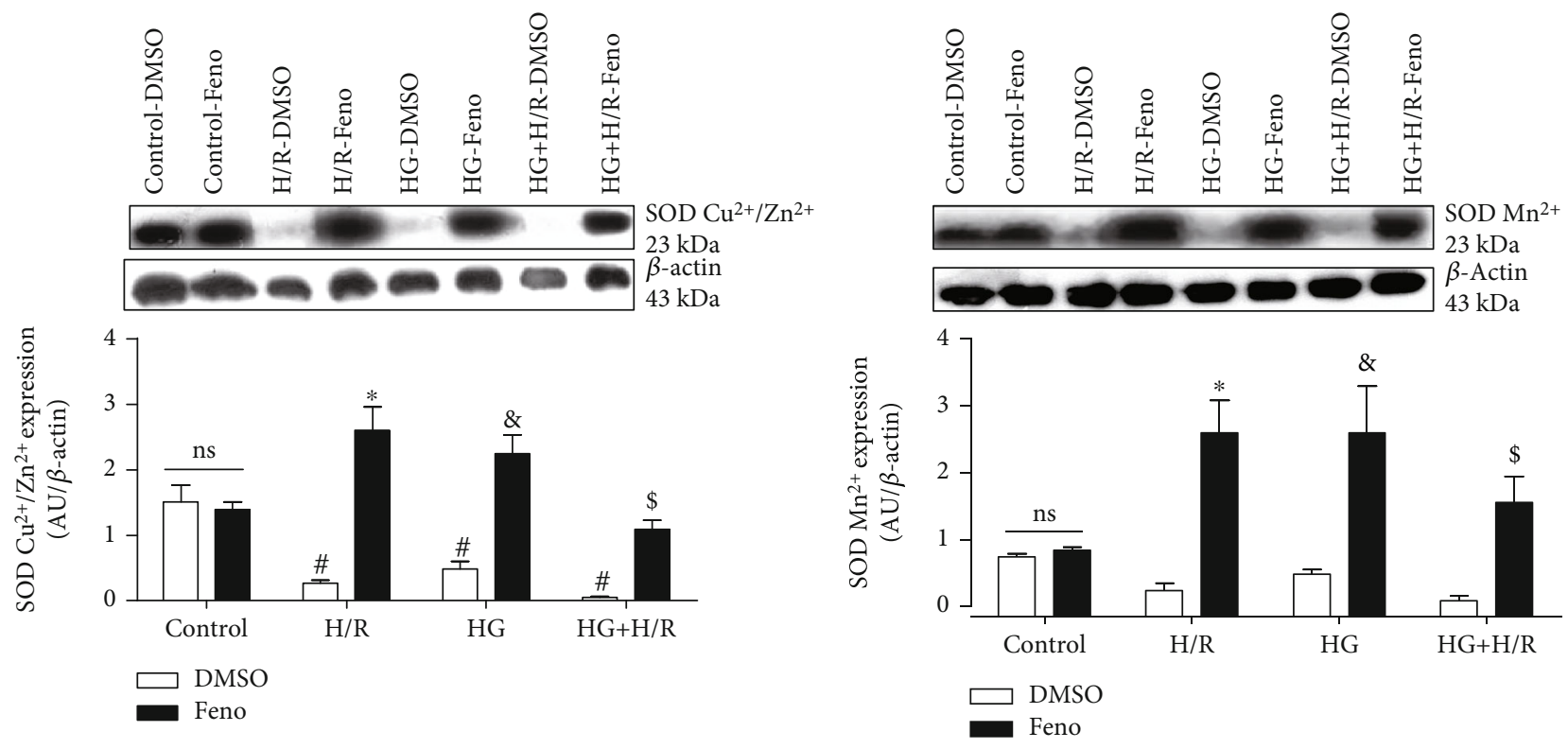

(a)

(b)
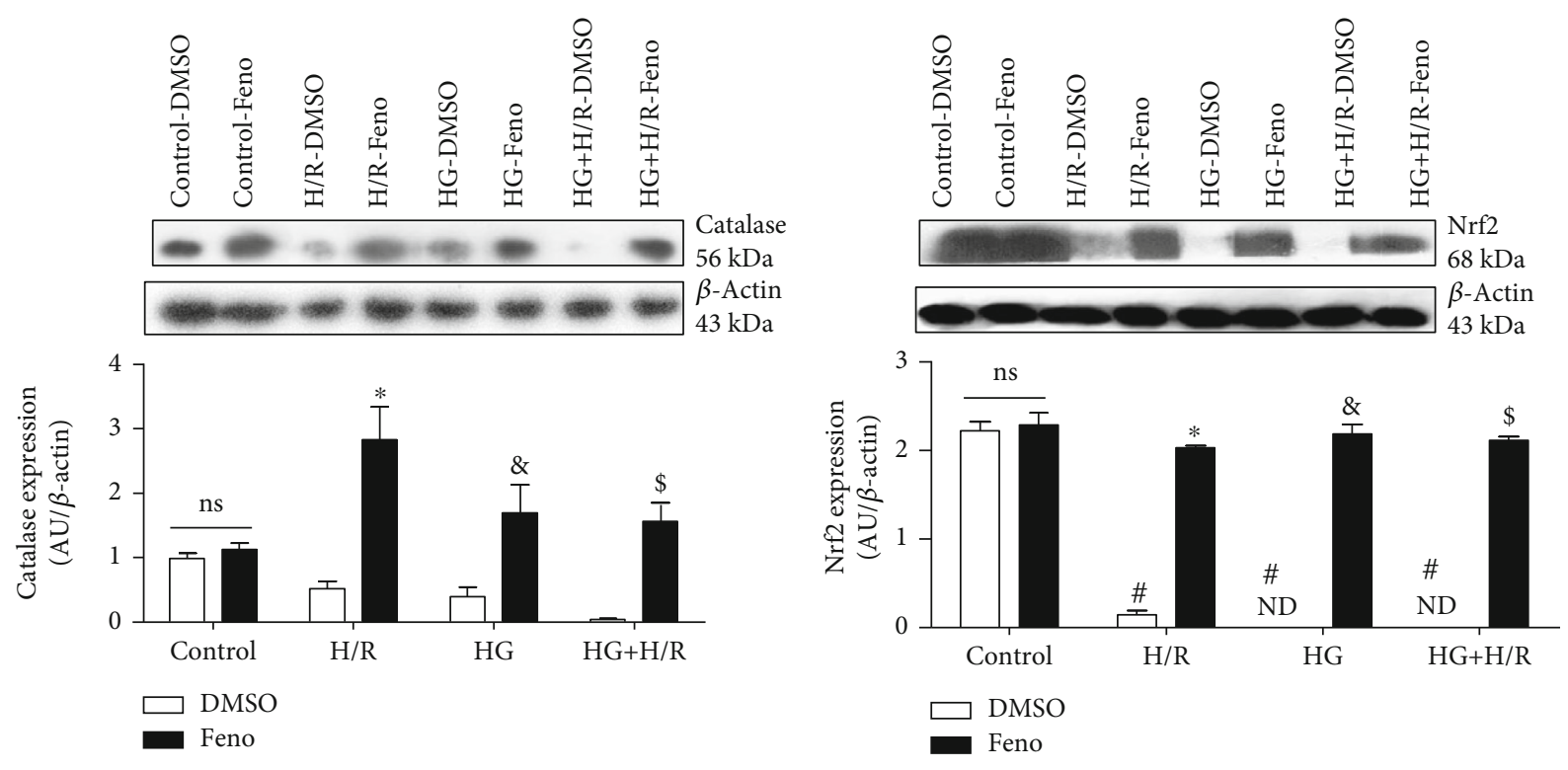

(c)

(d)

Figure 5: Continued. 


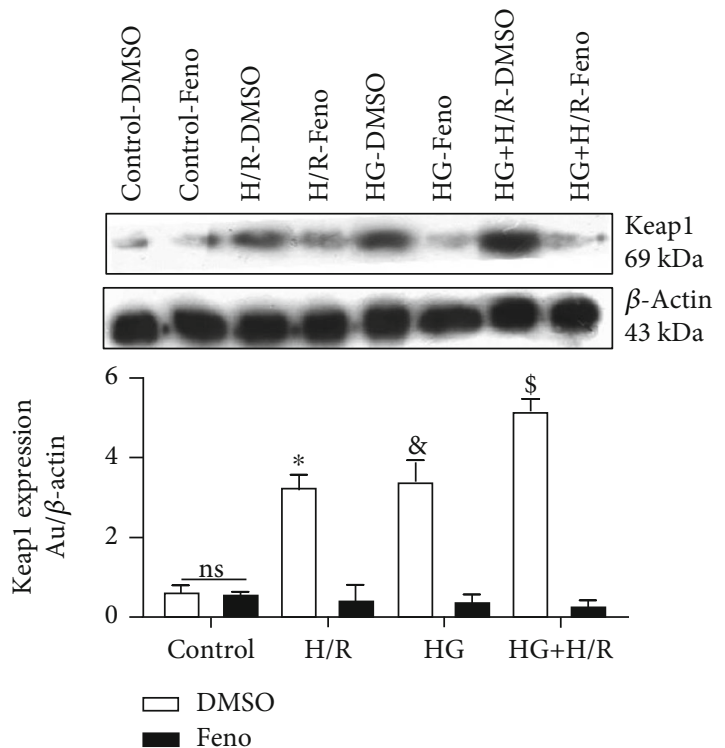

(e)

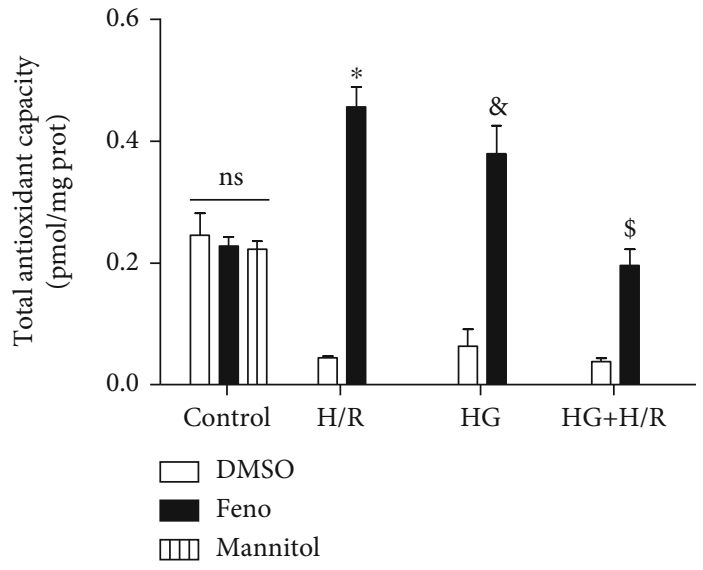

(f)

FIGURE 5: Fenofibrate $(10 \mu \mathrm{M})$ increased antioxidant defense in primary cultures of cardiomyocytes subjected to hypoxia/reperfusion (H/R), high glucose (HG), or the combination of conditions (HG+H/R). Protein expression by Western blot and densitometric analysis of (a) SOD $\mathrm{Cu}^{2+} / \mathrm{Zn}^{2+}$, (b) SOD $\mathrm{Mn}^{2+}$, (c) catalase, (d) Nrf2, (e) Keap1, and (f) total antioxidant capacity. ND = not detectable; DMSO = dimethylsulfoxide $(0.1 \%)$; Feno $=$ fenofibrate $(10 \mu \mathrm{M}) .{ }^{*} p<0.05$ vs. control-DMSO; ${ }^{*} p<0.05$ vs. H/R-DMSO; ${ }^{\&} p<0.05$ vs. HG-DMSO; $\$ p<0.05$ vs. HG+H/R-DMSO. Values represent the mean \pm SEM of 6 different experiments. Two-way analysis of variance (ANOVA) followed by Tukey's post hoc test.

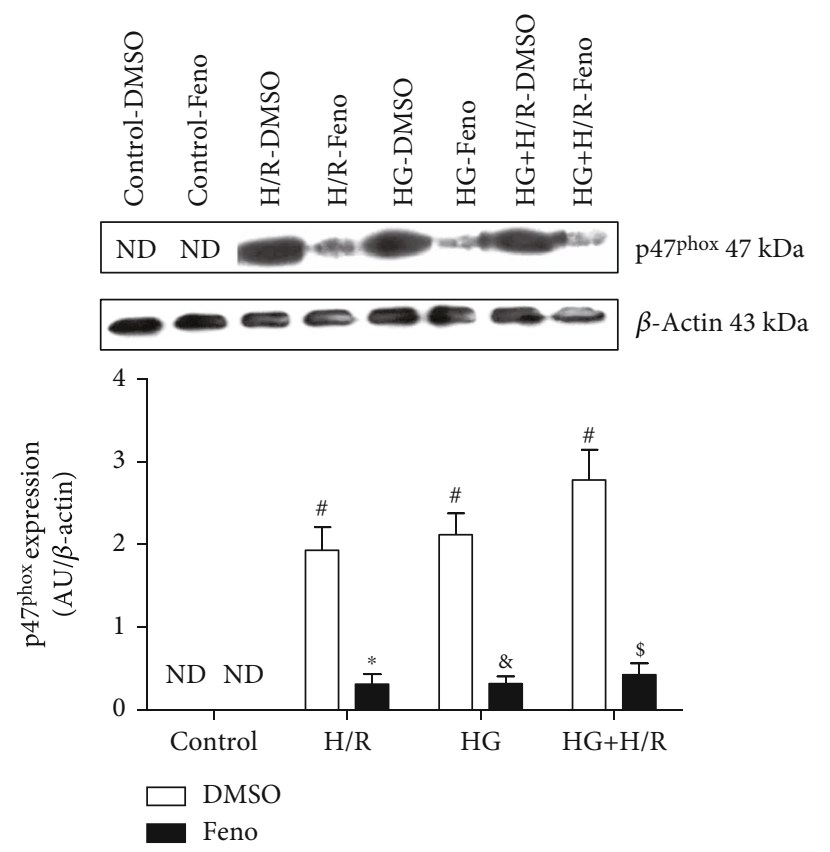

(a)
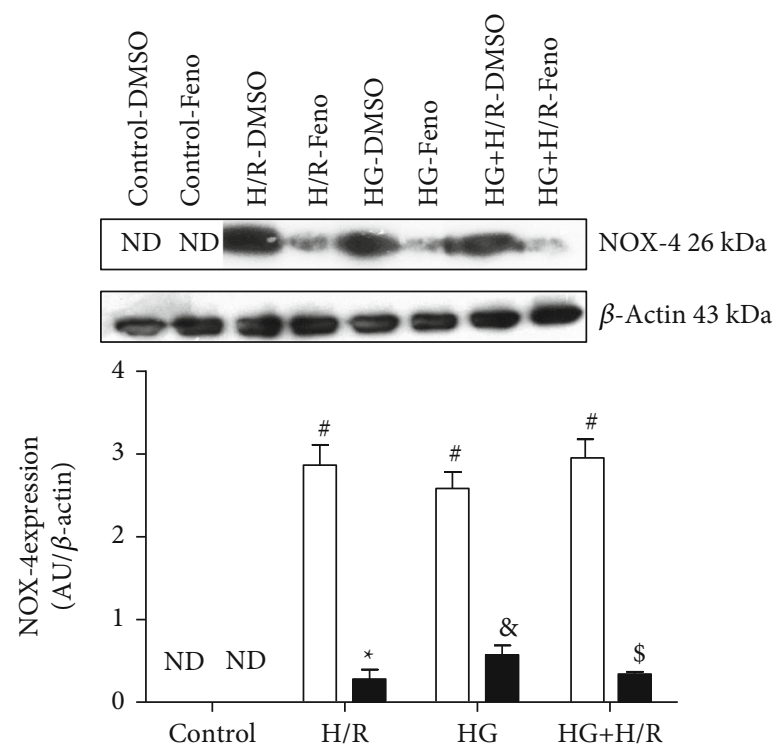

$\square$ DMSO

FIGURE 6: Fenofibrate $(10 \mu \mathrm{M})$ decreased the expression of the NADPH oxidase subunits in primary cultures of cardiomyocytes undergoing hypoxia/reperfusion (H/R), high glucose (HG), and the combination of both conditions (HG+H/R). (a) Protein expression and densitometric analysis of the p47phox subunit expression. (b) Protein expression and densitometric analysis of the NOX4 subunit expression. ND $=$ not detectable; DMSO = dimethylsulfoxide $(0.1 \%) ;$ Feno $=$ fenofibrate $(10 \mu \mathrm{M}) .{ }^{\#} p<0.05$ vs. control-DMSO; ${ }^{*} p<0.05$ vs. H/R-DMSO; ${ }^{\&} p<0.05$ vs. HG-DMSO; ${ }^{\$} p<0.05$ vs. HG+H/R-DMSO. Values represent the mean \pm SEM of 6 different experiments. Two-way analysis of variance (ANOVA) followed by Tukey's post hoc test. 


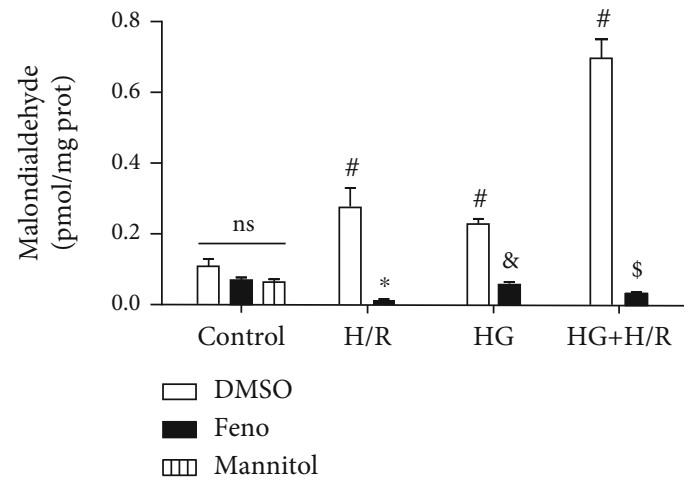

(a)

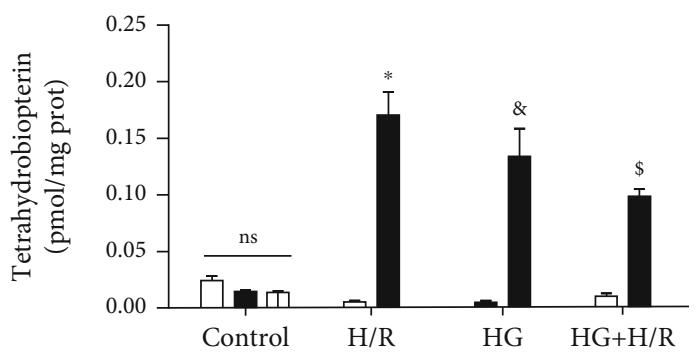

(c)

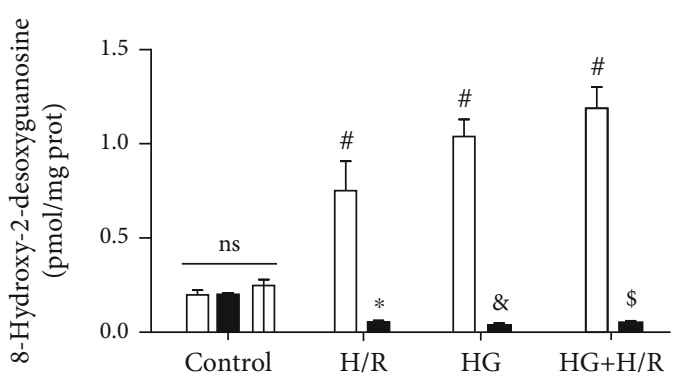

(b)

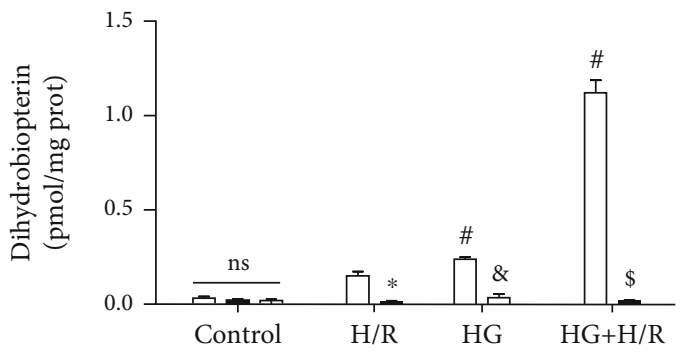

(d)

Figure 7: Fenofibrate $(10 \mu \mathrm{M})$ decreased the production of oxidant markers and prevented $\mathrm{BH}_{4}$ oxidation in primary cultures of cardiomyocytes undergoing hypoxia/reperfusion (H/R), high glucose (HG), and HG+H/R. (a) Malondialdehyde, (b) 8-hydroxy-2deoxyguanosine, (c) $\mathrm{BH}_{4}$, and (d) $\mathrm{BH}_{2}$ levels were measured by capillary zone electrophoresis. DMSO = dimethylsulfoxide $(0.1 \%)$; Feno = fenofibrate $(10 \mu \mathrm{M}) .{ }^{*} p<0.05$ vs. control-DMSO; ${ }^{*} p<0.05$ vs. H/R-DMSO; ${ }^{*} p<0.05$ vs. HG-DMSO; ${ }^{\$} p<0.05$ vs. HG+H/R-DMSO. Values represent the mean \pm SEM of 6 different experiments. Two-way analysis of variance (ANOVA) followed by Tukey's post hoc test.

improved the condition of mitochondria in cultured cells exposed to $H / R$, being observed dense although slightly reduced in size and elongated. In this case, the inner and outer membranes exhibited continuous borders. These characteristics indicate that mitochondria were functional (Figure 10(b)). Exposure to HG caused smaller and swollen mitochondria with signs of vacuolation (Figure 10(c)). In the HG-fenofibrate-exposed cardiomyocytes, it was observed that mitochondria were normal in size and density, indicating that the mitochondria were functional. Cardiomyocytes subjected to $\mathrm{HG}+\mathrm{H} / \mathrm{R}$ exhibited small and lysed mitochondria, further showing that the coexistence of both experimental conditions damages the ultrastructure of cardiomyocytes. Cardiomyocytes exposed to $\mathrm{HG}+\mathrm{H} / \mathrm{R}$ and treated with fenofibrate were small but exhibited dense mitochondria, without disruption of their membrane. These results indicate that fenofibrate protected the cardiomyocyte, especially mitochondria from $\mathrm{HG}$ and $\mathrm{H} / \mathrm{R}$-induced damage (Figure 10(d)).

\section{Discussion}

In the present work, we established an in vitro model using neonatal rat cardiomyocytes exposed to $\mathrm{HG}, \mathrm{H} / \mathrm{R}$, and the combination of both conditions to mimic the pathological features present in diabetes mellitus and myocardial infarction. Under these conditions, we demonstrated that treatment with fenofibrate exerts a protective effect in cardi- omyocytes by promoting an antioxidant environment and preserving the mitochondrial ultrastructure, through the upregulation of the master antioxidant genes PPAR $\alpha$ and Nrf2, events that contribute to the attenuation of cell death caused by $\mathrm{HG}+\mathrm{H} / \mathrm{R}$ injury.

Several experimental models reproduce, at different levels, the pathological conditions present in diabetes mellitus (DM) and myocardial infarction (MI). When performing cell cultures, the physiological, biochemical, and genetic properties of the cells are maintained to the maximum. In addition, the characteristic architecture of the tissue is maintained, preserving cellular interactions. The advantage of cell culture over other models lies in the precise and fine control of experimental conditions in the cellular environment $(\mathrm{pH}$, temperature, osmotic pressure, oxygen levels, $\mathrm{CO}_{2}$, etc.) [32]. As reported by Pitts and Toombs, hypoxia/reperfusion in cell cultures can be produced by placing a coverslip on top of the media; it creates a barrier to the diffusion of oxygen, immediately producing hypoxia and metabolic by-products, thus resembling the conditions of ischemia in vivo. Meanwhile, reperfusion is achieved by restoring oxygen concentrations [23].

Hyperglycemia is an important risk factor for acute myocardial infarction. It enhances oxidative stress, stimulates nitric oxide synthase uncoupling, increases mitochondrial derangement, and impairs prosurvival cell signaling in the diabetic myocardium, making it more vulnerable to ischemia-reperfusion injury [33]. Luan et al. identified that 


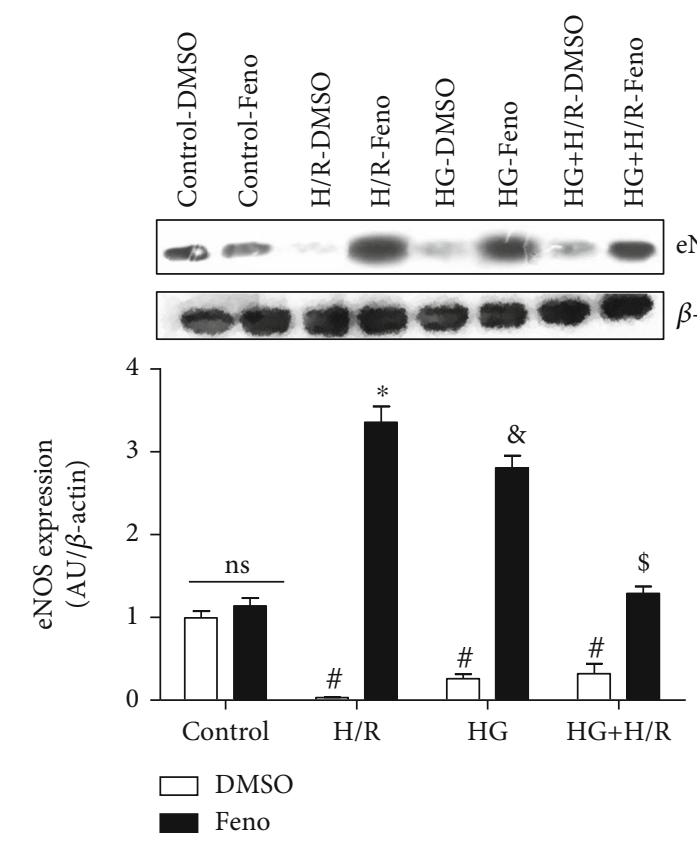

(a)
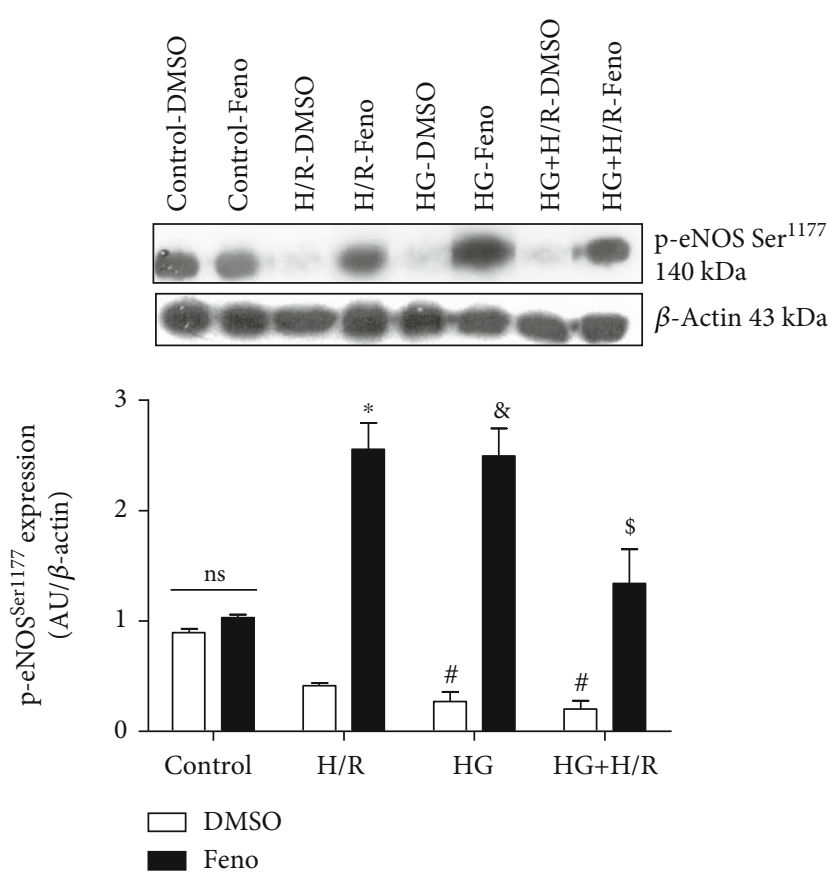

(b)

FIGURE 8: Fenofibrate $(10 \mu \mathrm{M})$ increases the expression of endothelial nitric oxide synthase (eNOS) and p-eNOS ${ }^{\text {Ser1177 }}$ in primary cultures of cardiomyocytes undergoing hypoxia/reperfusion (H/R), high glucose (HG), and HG+H/R. Protein expression and densitometric analysis of (a) total eNOS and (b) phospho-eNOS ${ }^{\text {Ser1 } 177}$ were performed. DMSO $=$ dimethylsulfoxide $(0.1 \%)$; Feno $=$ fenofibrate $(10 \mu \mathrm{M}) .{ }^{\#} p<0.05$ vs. control-DMSO; ${ }^{*} p<0.05$ vs. H/R-DMSO; ${ }^{\&} p<0.05$ vs. HG-DMSO; ${ }^{\$} p<0.05$ vs. HG+H/R-DMSO. Values represent the mean \pm SEM of 6 different experiments. Two-way analysis of variance (ANOVA) followed by Tukey's post hoc test.
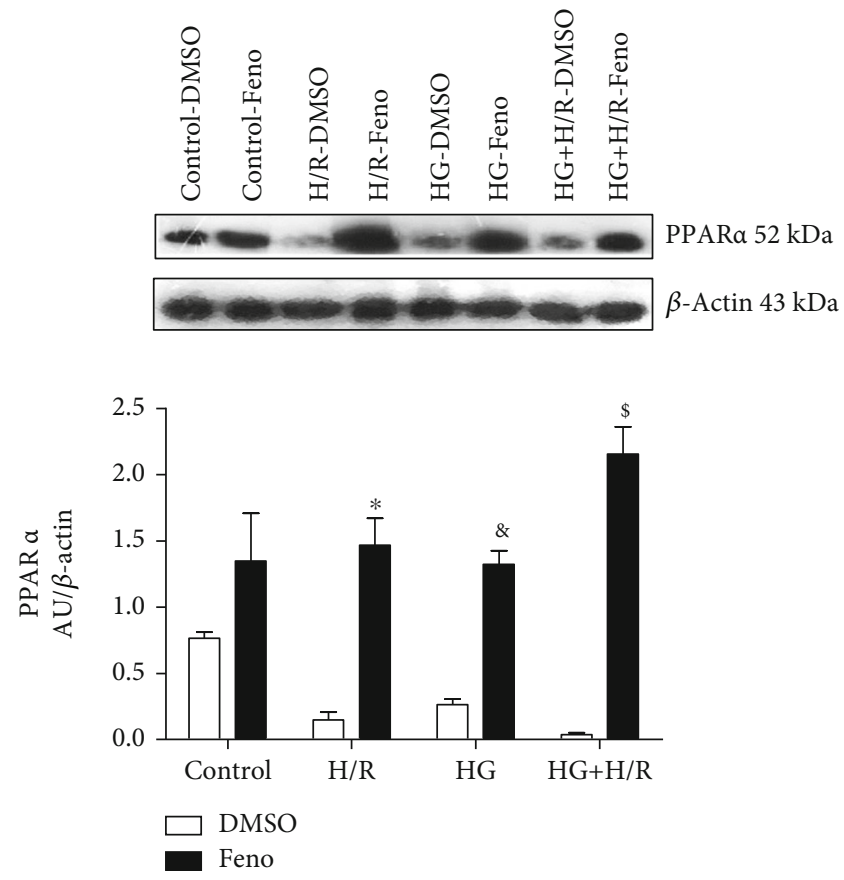

(a)
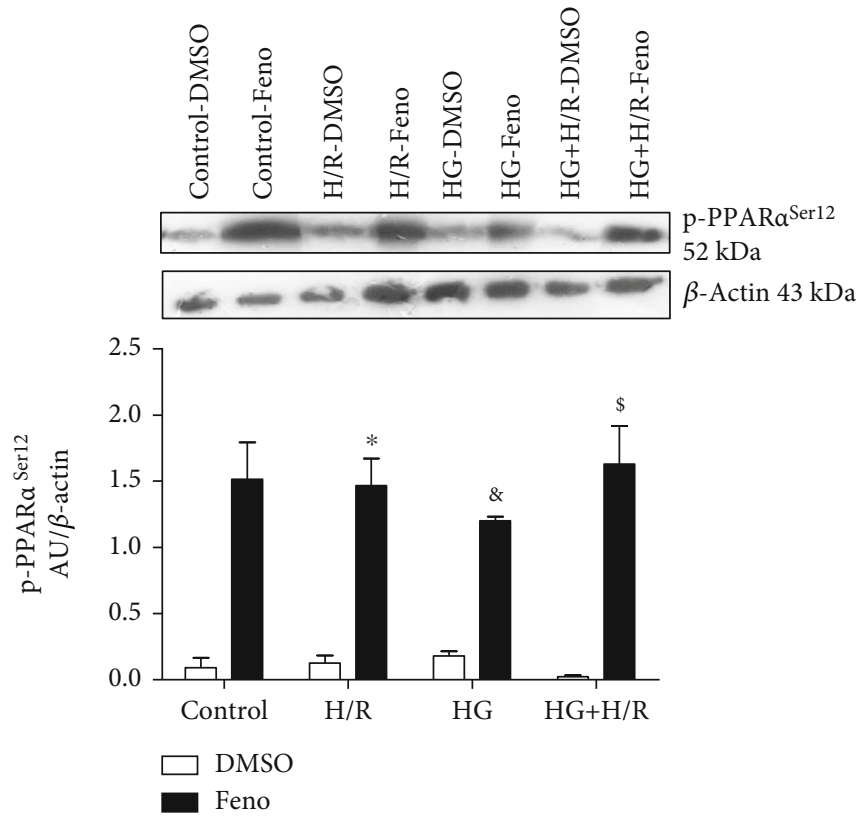

(b)

FIGURE 9: Fenofibrate $(10 \mu \mathrm{M})$ increases peroxisome proliferator-activated receptor alpha (PPAR $\alpha)$ and phospho-PPAR $\alpha^{\text {Ser12 }}$ expression in primary cultures of cardiomyocytes undergoing hypoxia/reperfusion (H/R), high glucose (HG), and HG+H/R. Protein expression and densitometric analyses of (a) PPAR $\alpha$ and (b) phospho-PPAR $\alpha^{\text {Ser12 }}$ were performed. DMSO $=$ dimethylsulfoxide $(0.1 \%)$; Feno $=$ fenofibrate $(10 \mu \mathrm{M}) .{ }^{\#} p<0.05$ vs. control-DMSO; ${ }^{*} p<0.05$ vs. H/R-DMSO; ${ }^{\&} p<0.05$ vs. HG-DMSO; ${ }^{\$} p<0.05$ vs. HG+H/R-DMSO. Values represent the mean \pm SEM of 6 different experiments. Two-way analysis of variance (ANOVA) followed by Tukey's post hoc test. 

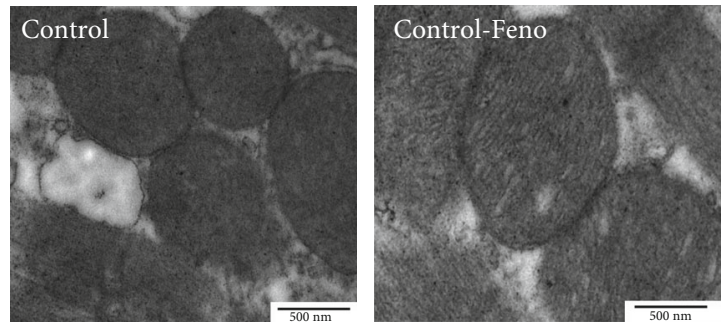

(a)
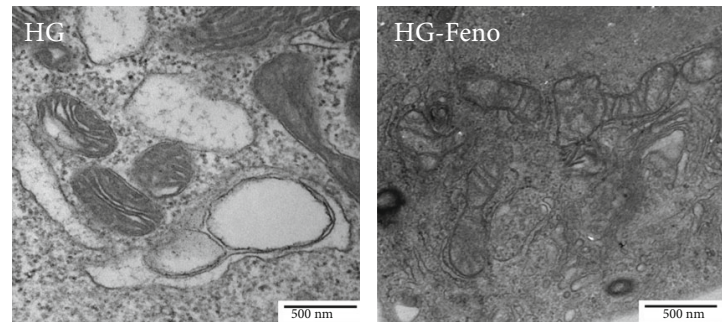

(c)
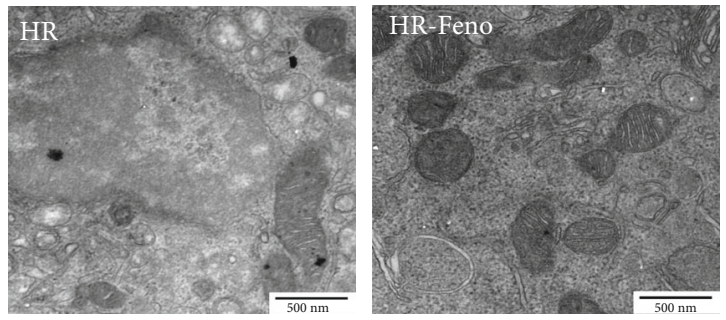

(b)
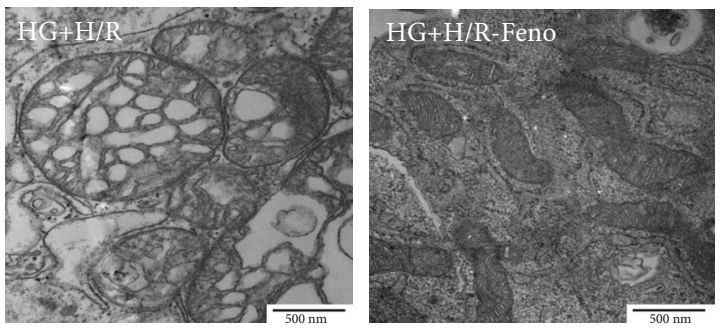

(d)

Figure 10: Fenofibrate $(10 \mu \mathrm{M})$ attenuates damage to the mitochondrial ultrastructure in primary cultures of cardiomyocytes subjected to hypoxia/reperfusion (H/R), high glucose (HG), and HG+H/R. Details of the ultrastructure by electron microscopy: $500 \mathrm{~nm}$, 50,000x. (a) Control-DMSO and control/fenofibrate, (b) H/R-DMSO and H/R-fenofibrate, (c) HG-DMSO and HG-fenofibrate, and (d) HG+H/RDMSO and $\mathrm{HG}+\mathrm{H} / \mathrm{R}$-fenofibrate. The images are representative of 6 experiments per group.

HG treatment sensitized adult cardiomyocytes to ischemia/reperfusion (I/R) injury [34].

Myocardial hypoxia results in metabolic changes and irreversible damage leading to cardiomyocyte death [35]. Hypoxia not only damages the heart but other organs as well; fenofibrate has been tried and used as the drug of choice to reduce the effects of $H / R$ in various organs, as demonstrated by Bhalodia et al., who provided evidence that fenofibrate exerted renoprotective effects on hypoxia/reperfusion injury (H/R). Therefore, this drug not only protects the heart from $\mathrm{H} / \mathrm{R}$ but also protects the kidney subjected to the same conditions [36]. Fenofibrate has been reported to promote an antioxidant, anti-inflammatory, and anti-ischemic effect in a model of intestinal IR injury in rats [37], improving the intestinal recovery and the enterocyte turnover. Furthermore, studies have highlighted the pleiotropic vascular endothelial protective and antihypertensive actions of fenofibrate [38].

In our study, the success of the technique used to produce hypoxia was verified evaluating HIF- $1 \alpha$ expression. HIF- $1 \alpha$ is a transcription factor that regulates the cellular response to hypoxia and acts as a regulator of oxygen homeostasis. Our results indicate that the method used to produce hypoxia (coverslips) significantly increased the expression of this factor in cell cultures subjected to hypoxia (Figures 2(a) and 2(b)). This result is in agreement with that reported by Jia et al. [39]. They studied a rat model of intestinal ischemia/reperfusion (I: 1 hour/R: 2 hours), and their results show that the expression of HIF- $1 \alpha$ increased in rats with I/R compared to controls.

It is widely reported that $\mathrm{H} / \mathrm{R}$ causes cell death. A well accepted technique to evaluate this event is the cellular exclusion of trypan blue dye used by Zhang et al. [6], where H9c2 cells were subject to $\mathrm{H} / \mathrm{R}$ and $\mathrm{HG}(55 \mathrm{mmol} / \mathrm{L})$. Our results reproduce the detrimental effects of $H G$ and $H / R$, reported by Zhang et al., and exhibit the extension of the event when the two pathological factors coexist. We observed that in those cardiomyocytes exposed 48 hours to HG and lately to fenofibrate (4 hours), there was no protection (Figure 3). Probably, the lack of effect exerted by fenofibrate would be related to hyperglycemia-induced metabolic memory. This metabolic memory increases fibronectin, inflammatory mediators, vascular endothelial growth factor, and intercellular adhesion molecule-1 (ICAM-1); these effects are sustained following normalization of glucose levels in the window of days to weeks [40, 41]. According to Kim et al. [42], chronic high glucose reduced PPAR binding to target genes.

Our results showed that $\mathrm{H} / \mathrm{R}, \mathrm{HG}$, and the combination of both conditions increased the production of ROS (Figure 4). This result is similar to that obtained by Wang et al. [43] who observed higher levels of ROS in H9C2 cells subjected to H/R compared to those of control cell cultures. The authors also reported the diminished expression of SOD $\mathrm{Mn}^{2+}$, resulting in oxidative damage to the cardiomyocytes. A similar result was obtained by Zhou et al. [44] in cardiomyocytes from Sprague-Dawley rats exposed to HG $(30 \mathrm{mmol} / \mathrm{L})$. Our research extended those observations to the combination of both pathological conditions and the effect of fenofibrate treatment on oxidative stress, showing increased antioxidant enzyme expression as well as raised antioxidant capacity (Figures 5(a), 5(b), 5(c), and 5(f)). The expression of Keap1/Nrf2 was also evaluated. The transcription factor Nrf2 regulates the inducible expression of numerous detoxifying and antioxidant genes. It binds to a specific DNA sequence known as ARE (Antioxidant Response Element) that can be activated by several electrophils and oxidant compounds of diverse chemical nature. Nrf2 

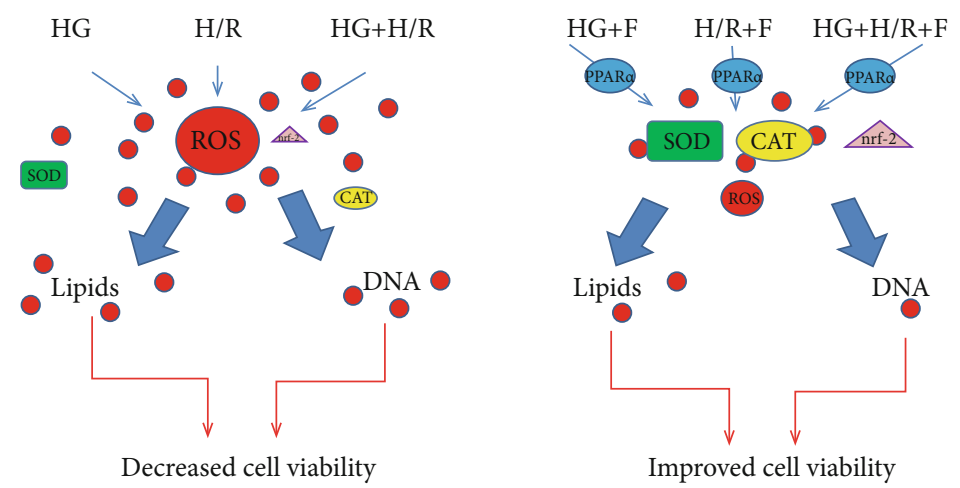

Figure 11: A schematic diagram proposing the mechanism of action of fenofibrate in $\mathrm{H} / \mathrm{R}, \mathrm{HG}$, and $\mathrm{HG}+\mathrm{H} / \mathrm{R}$ in cardiomyocyte cell culture.

activation is constitutively repressed by its binding with a cytosolic protein known as Keap1 and to the cytoskeleton. This interaction promotes the permanent Nrf2 degradation by the proteosome, implying that the primary control of Nrf2 function lies on its subcellular distribution rather on its de novo synthesis. Additionally, it has been suggested that the Keap1/Nrf2 system contributes to the protection in pathologies like DM and ischemia. In fact, the Nrf2mediated antioxidant response is one of the main cellular defense mechanisms that facilitates cell survival under toxic attacks [45]. Our results indicate that this factor decreases in $\mathrm{HG}, \mathrm{H} / \mathrm{R}$, and the coexistence of both conditions; however, treatment with fenofibrate significantly increased its expression (Figure 5(d)). He et al. [45] cultured cardiomyocytes from $\mathrm{Nrf}^{-/-}$knockout (KO) and wild-type (WT) mice and exposed them to HG levels ( $40 \mathrm{mM})$. Cardiomyocytes lacking the expression of Nrf2 exhibited a remarkably high level of ROS compared to WT cardiomyocyte cultures. Nrf2 also plays a role in cardiac protection against H/R. Xu et al. [46] showed that Nrf2 $\mathrm{KO}$ mice developed a larger infarct size posterior to ischemia/reperfusion. In addition, a recent study [47] showed that fenofibrate attenuates oxidative stress in diabetic retinopathy through Keap1/Nrf2, suggesting that cardiomyocytes stimulated by fenofibrate were protected from oxidative stress following a pathway that includes Nrf2. Our results also showed that Keap1 is increased in cardiomyocytes with pathological conditions, while treatment with fenofibrate decreased its expression. This result is similar to that found by $\mathrm{Wu}$ et al. [48], where PPAR $\alpha$ regulates the pathway Keap1/NRF2.

One of the most active enzymes in ROS production is NADPH oxidase $[49,50]$. Our results show that cardiomyocytes exposed to $\mathrm{H} / \mathrm{R}, \mathrm{HG}$, and $\mathrm{HG}+\mathrm{H} / \mathrm{R}$ overexpressed NADPH oxidase subunits, namely, 47phox and NOX4, an event that was decreased by fenofibrate stimulation (Figure 6). Current results agree with previous reports from our laboratory showing that clofibrate treatment to Wistar rats subjected to myocardial infarction reduces the expression of NADPH oxidase subunits [15].

In our study, we assessed the damage to important macromolecules in cells such as lipids and DNA. Our results indicate that $\mathrm{H} / \mathrm{R}, \mathrm{HG}$, and $\mathrm{HG}+\mathrm{H} / \mathrm{R}$-induced damage to lipids and DNA increased (Figures $7(\mathrm{a})$ and $7(\mathrm{~b})$ ), as well as the oxidation of the cofactor $\mathrm{BH}_{4}$, which is observed as an increased content of $\mathrm{BH}_{2}$ (Figures $7(\mathrm{c})$ and $7(\mathrm{~d})$ ). The stimulation with fenofibrate reduced the oxidative damage to those molecules. Previous studies $[51,52]$ show that the lower bioavailability of $\mathrm{BH}_{4}$ not only prevents the formation of $\mathrm{NO}$ by eNOS but also increases the formation of ROS, further producing damage to the cardiomyocytes. Additionally, previous reports [53] showed that hypoxia activates cellular proteases which may degrade eNOS. Goya et al. [54] demonstrated that WY14643, a PPAR $\alpha$ agonist, increased eNOS expression in bovine aortic endothelial cells. In agreement with the observations of Goya et al., our data show that cardiomyocytes exposed to fenofibrate raised eNOS and p-eNOS ${ }^{\text {Ser1177 }} \mathrm{de}$ spite being exposed to pathological conditions (HG, H/R, $\mathrm{HG}+\mathrm{H} / \mathrm{R}$ ) (Figures 8(a) and 8(b)).

Importantly, it has been reported that the phosphorylation of PPAR $\alpha$ on Ser12 increases its activity and correlates with increased transactivation of PPAR $\alpha$ in cardiomyocytes [55]. Our results indicate that fenofibrate increases the expression of PPAR $\alpha$ and $\operatorname{p-PPAR} \alpha^{\operatorname{Ser} 12}$, while $H / R, H G$, and the combination of both conditions decrease their expression (Figures 9(a) and 9(b)). The rise in p-PPAR $\alpha^{\text {Ser12, }}$ and therefore the activation of $\operatorname{PPAR} \alpha$, correlates with the increased expression of the antioxidant enzymes (SOD and catalase) and transcription factors like Nrf2, which have been reported to contain a PPAR response element in their sequences. Consequently, the activation of $\operatorname{PPAR} \alpha$ is fundamental for cardiac functions by promoting the homeostatic balance between ROS and antioxidants $[56,57]$.

Fenofibrate attenuated mitochondrial damage caused by HG, H/R, and the coexistence of both pathological factors (Figure 10). We hypothesize that the lower damage observed in cardiomyocytes is due to (1) decreased oxidative stress, a consequence of reduced expression of NADPH oxidase enzyme subunits and higher antioxidant defense, where Nrf2 plays an important role; (2) lower damage to macromolecules such as membrane lipids and DNA; and (3) higher expression of p-eNOS ${ }^{\text {Ser1177 }}$. These events could contribute to mitochondrial protection, further supporting the reports of Holmstrom et al. [58], Li et al. [59], and Ilangovan et al. [60].

Currently, there are human studies proving the effectiveness of fenofibrate; for instance, the action to control cardiovascular risk in diabetes (ACCORD STUDY) demonstrated a $40 \%$ reduction in the progression of proliferative diabetic 
retinopathy in type 2 diabetic patients using fenofibrate treatment [61]. Fenofibrate intervention decreases the incidence of myocardial infarction and reduces the risk of subsequent clinical cardiovascular events in patients with type 2 diabetes [62].

However, the use of fenofibrate to reduce the incidence of cardiovascular events in diabetic patients has been controversial due to the heterogeneity of the treatment's response in clinical trials $[63,64]$.

In summary, the effect of fenofibrate on the pathologies under study are illustrated in Figure 11.

\section{Conclusions}

According to our results, we can conclude that $\mathrm{H} / \mathrm{R}, \mathrm{HG}$, and the coexistence of both pathologies generate oxidative stress in cardiomyocytes leading to lower cell viability. Further, fenofibrate treatment improves cell viability and favors an antioxidant environment contributing to preserve cardiac ultrastructure.

\section{Data Availability}

The datasets generated during the study are available from corresponding author on reasonable request.

\section{Conflicts of Interest}

The authors declare no conflict of interest.

\section{Authors' Contributions}

Fabiola Cortes-Lopez and Alicia Sanchez-Mendoza contributed equally to this work.

\section{Acknowledgments}

This study was supported by Consejo Nacional de Ciencia y Tecnología-México (CONACyT-México) research grants 222720 and 280458 to AS-M.

\section{References}

[1] S. Erqou, C. T. Lee, M. Suffoletto et al., "Association between glycated haemoglobin and the risk of congestive heart failure in diabetes mellitus: systematic review and meta-analysis," European Journal of Heart Failure, vol. 15, no. 2, pp. 185193, 2013.

[2] A. J. Wilson, E. K. Gill, R. A. Abudalo, K. S. Edgar, C. J. Watson, and D. J. Grieve, "Reactive oxygen species signalling in the diabetic heart: emerging prospect for therapeutic targeting," Heart, vol. 104, no. 4, pp. 293-299, 2018.

[3] T. Finkel, "Signal transduction by reactive oxygen species," The Journal of Cell Biology, vol. 194, no. 1, pp. 7-15, 2011.

[4] K. Sada, T. Nishikawa, D. Kukidome et al., "Hyperglycemia induces cellular hypoxia through production of mitochondrial ROS followed by suppression of aquaporin-1," PLoS One, vol. 11, no. 7, p. e0158619, 2016.

[5] R. M. Maalouf, A. A. Eid, Y. C. Gorin et al., "Nox4-derived reactive oxygen species mediate cardiomyocyte injury in early type 1 diabetes," American Journal of Physiology. Cell Physiology, vol. 302, no. 3, pp. C597-C604, 2012.

[6] M. Zhang, A. L. Kho, N. Anilkumar et al., "Glycated proteins stimulate reactive oxygen species production in cardiac myocytes: involvement of Nox2 (gp91phox)-containing NADPH oxidase," Circulation, vol. 113, no. 9, pp. 1235-1243, 2006.

[7] F. Giacco, X. du, A. Carratú et al., "GLP-1 cleavage product reverses persistent ROS generation after transient hyperglycemia by disrupting an ROS-generating feedback loop," Diabetes, vol. 64, no. 9, pp. 3273-3284, 2015.

[8] J. Biddlestone, D. Bandarra, and S. Rocha, "The role of hypoxia in inflammatory disease (review)," International Journal of Molecular Medicine, vol. 35, no. 4, pp. 859-869, 2015.

[9] B. Zhang, M. Zhai, B. Li et al., "Honokiol ameliorates myocardial ischemia/reperfusion injury in type 1 diabetic rats by reducing oxidative stress and apoptosis through activating the SIRT1-Nrf2 signaling pathway," Oxidative Medicine and Cellular Longevity, vol. 2018, Article ID 3159801, 2018.

[10] J. Berger and D. E. Moller, "The mechanisms of action of PPARs," Annual Review of Medicine, vol. 53, no. 1, pp. 409435, 2002.

[11] J. P. Berger, T. E. Akiyama, and P. T. Meinke, "PPARs: therapeutic targets for metabolic disease," Trends in Pharmacological Sciences, vol. 26, no. 5, pp. 244-251, 2005.

[12] V. Costa, D. Foti, F. Paonessa et al., "The insulin receptor: a new anticancer target for peroxisome proliferator-activated receptor-gamma (PPARgamma) and thiazolidinedionePPARgamma agonists," Endocrine-Related Cancer, vol. 15, no. 1, pp. 325-335, 2008.

[13] S. A. Kliewer, K. Umesono, D. J. Noonan, R. A. Heyman, and R. M. Evans, "Convergence of 9-cis retinoic acid and peroxisome proliferator signalling pathways through heterodimer formation of their receptors," Nature, vol. 358, no. 6389, pp. 771-774, 1992.

[14] N. Latruffe, M. C. Malki, V. Nicolas-Frances, M. C. Clemencet, B. Jannin, and J. P. Berlot, "Regulation of the peroxisomal $\beta$ oxidation-dependent pathway by peroxisome proliferatoractivated receptor $\alpha$ and kinases," Biochemical Pharmacology, vol. 60, no. 8, pp. 1027-1032, 2000.

[15] L. Ibarra-Lara, M. Sánchez-Aguilar, A. Sánchez-Mendoza et al., "Fenofibrate therapy restores antioxidant protection and improves myocardial insulin resistance in a rat model of metabolic syndrome and myocardial ischemia: the role of angiotensin II," Molecules, vol. 22, no. 1, p. 31, 2017.

[16] L. Ibarra-Lara, E. Hong, E. Soria-Castro et al., "Clofibrate $\operatorname{PPAR} \alpha$ activation reduces oxidative stress and improves ultrastructure and ventricular hemodynamics in no-flow myocardial ischemia," Journal of Cardiovascular Pharmacology, vol. 60, no. 4, pp. 323-334, 2012.

[17] P. Drouin, L. Mejean, D. Lambert, J. P. Sauvanet, and G. Debry, "Effect of procetofen on the lipoprotein profile in patients with type II hyperlipoproteinemia," Die Medizinische Welt, vol. 30, no. 50, pp. 1910-1913, 1979.

[18] P. Drouin, D. Lambert, L. Mejean, J. P. Pointel, and G. Debry, "Study of lipid metabolic coefficient K2 in patients with hyperlipoproteinemia type IV before and after reduction of triglyceride level by adapted diet therapy," Nutrition and Metabolism, vol. 23, no. 5, pp. 416-428, 1979.

[19] E. Aasum, A. M. Khalid, O. A. Gudbrandsen, O. J. How, R. K. Berge, and T. S. Larsen, "Fenofibrate modulates cardiac and hepatic metabolism and increases ischemic tolerance in diet- 
induced obese mice," Journal of Molecular and Cellular Cardiology, vol. 44, no. 1, pp. 201-209, 2008.

[20] M. Garg, D. Khanna, S. Kalra, and P. Balakumar, "Chronic oral administration of low-dose combination of fenofibrate and rosuvastatin protects the rat heart against experimentally induced acute myocardial infarction," Fundamental \& Clinical Pharmacology, vol. 30, no. 5, pp. 394-405, 2016.

[21] I. A. Bukhari, A. A. Almotrefi, O. Y. Mohamed, A. A. Al-Masri, and S. A. Sheikh, "Protective effect of fenofibrate against ischemia-/reperfusion-induced cardiac arrhythmias in isolated rat hearts," Fundamental \& Clinical Pharmacology, vol. 32, no. 2, pp. 141-146, 2018.

[22] E. Ehler, T. Moore-Morris, and S. Lange, "Isolation and culture of neonatal mouse cardiomyocytes," Journal of Visualized Experiments, vol. 79, no. 79, 2013.

[23] K. R. Pitts and C. F. Toombs, "Coverslip hypoxia: a novel method for studying cardiac myocyte hypoxia and ischemia in vitro," American Journal of Physiology. Heart and Circulatory Physiology, vol. 287, no. 4, pp. H1801-H1812, 2004.

[24] K. R. Pitts, J. M. J. Derry, K. Kerkof, W. A. Lawrence, and C. F. Toombs, "Differentially regulated functional gene clusters identified during ischemia and reperfusion in isolated cardiac myocytes using coverslip hypoxia," Journal of Pharmacological and Toxicological Methods, vol. 57, no. 1, pp. 42-51, 2008.

[25] W. Strober, "Trypan blue exclusion test of cell viability," Current Protocols in Immunology, vol. 111, pp. A3 B 1-A3A3 B, 2015.

[26] L. C. Crowley, B. J. Marfell, M. E. Christensen, and N. J. Waterhouse, "Measuring cell death by trypan blue uptake and light microscopy," Cold Spring Harbor Protocols, vol. 2016, no. 7, p. pdb.prot087155, 2016.

[27] V. Ramírez, J. Trujillo, R. Valdes et al., “Adrenalectomy prevents renal ischemia-reperfusion injury," American Journal of Physiology. Renal Physiology, vol. 297, no. 4, pp. F932F942, 2009.

[28] C. A. Davison, S. M. Durbin, M. R. Thau et al., "Antioxidant enzymes mediate survival of breast cancer cells deprived of extracellular matrix," Cancer Research, vol. 73, no. 12, pp. 3704-3715, 2013.

[29] D. M. Okamura, N. M. Bahrami, S. Ren et al., "Cysteamine modulates oxidative stress and blocks myofibroblast activity in CKD," Journal of the American Society of Nephrology, vol. 25 , no. 1, pp. 43-54, 2014.

[30] M. Sánchez-Aguilar, L. Ibarra-Lara, L. del Valle-Mondragón et al., "Rosiglitazone, a Ligand to PPAR, Improves Blood Pressure and Vascular Function through Renin-Angiotensin System Regulation," PPAR Research, vol. 2019, Article ID 1371758, 2019.

[31] R. Apak, K. Guclu, M. Ozyurek, S. E. Karademir, and M. Altun, "Total antioxidant capacity assay of human serum using copper(II)-neocuproine as chromogenic oxidant: the CUPRAC method," Free Radical Research, vol. 39, no. 9, pp. 949-961, 2009.

[32] Y. Zhang, T. S. Li, S. T. Lee et al., "Dedifferentiation and proliferation of mammalian cardiomyocytes," PLoS One, vol. 5, no. 9, p. e12559, 2010.

[33] D. M. Ansley and B. Wang, "Oxidative stress and myocardial injury in the diabetic heart," The Journal of Pathology, vol. 229, no. 2, pp. 232-241, 2013.

[34] R. Luan, S. Liu, T. Yin et al., "High glucose sensitizes adult cardiomyocytes to ischaemia/reperfusion injury through nitrative thioredoxin inactivation," Cardiovascular Research, vol. 83, no. 2, pp. 294-302, 2009.

[35] J. Moreu-Burgos and C. Macaya-Miguel, "The pathophysiology of myocardial ischemia. The importance of heart rate," Revista Española de Cardiología, vol. 7, no. 4, pp. 19D-25D, 2007.

[36] Y. Bhalodia, N. Sheth, J. Vaghasiya, and N. Jivani, "Role of fenofibrate alone and in combination with telmisartan on renal ischemia/reperfusion injury," Renal Failure, vol. 32, no. 9, pp. 1088-1094, 2010.

[37] I. Sukhotnik, N. Nissimov, Y. Ben Shahar et al., "Fenofibrate reduces intestinal damage and improves intestinal recovery following intestinal ischemia-reperfusion injury in a rat," Pediatric Surgery International, vol. 32, no. 12, pp. 1193-1200, 2016.

[38] P. Balakumar, R. Sambathkumar, N. Mahadevan et al., "Molecular targets of fenofibrate in the cardiovascular-renal axis: a unifying perspective of its pleiotropic benefits," Pharmacological Research, vol. 144, pp. 132-141, 2019.

[39] Z. Jia, W. Lian, H. Shi et al., "Ischemic postconditioning protects against intestinal ischemia/reperfusion injury via the HIF-1 $\alpha /$ miR-21 axis," Scientific Reports, vol. 7, no. 1, p. 16190, 2017.

[40] R. A. Kowluru, Q. Zhong, and M. Kanwar, "Metabolic memory and diabetic retinopathy: role of inflammatory mediators in retinal pericytes," Experimental Eye Research, vol. 90, no. 5, pp. $617-623,2010$.

[41] A. el-Osta, D. Brasacchio, D. Yao et al., "Transient high glucose causes persistent epigenetic changes and altered gene expression during subsequent normoglycemia," The Journal of Experimental Medicine, vol. 205, no. 10, pp. 2409-2417, 2008.

[42] E. S. Kim, F. Isoda, I. Kurland, and C. V. Mobbs, "Glucoseinduced metabolic memory in Schwann cells: prevention by PPAR agonists," Endocrinology, vol. 154, no. 9, pp. 30543066, 2013.

[43] X. Wang, L. Yang, L. Kang et al., "Metformin attenuates myocardial ischemia-reperfusion injury via up-regulation of antioxidant enzymes," PLoS One, vol. 12, no. 8, p. e0182777, 2017.

[44] X. Zhou and X. Lu, "The role of oxidative stress in high glucose-induced apoptosis in neonatal rat cardiomyocytes," Experimental Biology and Medicine (Maywood, N.J.), vol. 238, no. 8, pp. 898-902, 2013.

[45] X. He, H. Kan, L. Cai, and Q. Ma, "Nrf2 is critical in defense against high glucose-induced oxidative damage in cardiomyocytes," Journal of Molecular and Cellular Cardiology, vol. 46, no. 1, pp. 47-58, 2009.

[46] B. Xu, J. Zhang, J. Strom, S. Lee, and Q. M. Chen, "Myocardial ischemic reperfusion induces de novo Nrf2 protein translation," Biochimica et Biophysica Acta, vol. 1842, no. 9, pp. 1638-1647, 2014.

[47] Q. Liu, X. Zhang, R. Cheng, J. X. Ma, J. Yi, and J. Li, "Salutary effect of fenofibrate on type 1 diabetic retinopathy via inhibiting oxidative stress-mediated $\mathrm{Wnt} / \beta$-catenin pathway activation," Cell and Tissue Research, vol. 376, no. 2, pp. 165-177, 2019.

[48] Q. Q. Wu, W. Deng, Y. Xiao et al., "The 5-lipoxygenase inhibitor zileuton protects pressure overload-induced cardiac remodeling via activating $\operatorname{PPAR} \alpha$," Oxidative Medicine and Cellular Longevity, vol. 2019, Article ID 7536803, 17 pages, 2019. 
[49] B. Lassegue and R. E. Clempus, "Vascular NAD(P)H oxidases: specific features, expression, and regulation," American Journal of Physiology. Regulatory, Integrative and Comparative Physiology, vol. 285, no. 2, pp. R277-R297, 2003.

[50] S. Kovac, P. R. Angelova, K. M. Holmstrom, Y. Zhang, A. T. Dinkova-Kostova, and A. Y. Abramov, "Nrf2 regulates ROS production by mitochondria and NADPH oxidase," Biochimica et Biophysica Acta, vol. 1850, no. 4, pp. 794-801, 2015.

[51] L. B. Esberg and J. Ren, "Role of nitric oxide, tetrahydrobiopterin and peroxynitrite in glucose toxicity-associated contractile dysfunction in ventricular myocytes," Diabetologia, vol. 46, no. 10, pp. 1419-1427, 2003.

[52] Y. Xia, A. L. Tsai, V. Berka, and J. L. Zweier, "Superoxide generation from endothelial nitric-oxide synthase. $\mathrm{A} \mathrm{Ca}^{2+} /-$ calmodulin-dependent and tetrahydrobiopterin regulatory process," The Journal of Biological Chemistry, vol. 273, no. 40, pp. 25804-25808, 1998.

[53] R. R. Giraldez, A. Panda, Y. Xia, S. P. Sanders, and J. L. Zweier, "Decreased nitric-oxide synthase activity causes impaired endothelium-dependent relaxation in the postischemic heart," The Journal of Biological Chemistry, vol. 272, no. 34, pp. 21420-21426, 1997.

[54] K. Goya, S. Sumitani, X. Xu et al., "Peroxisome proliferatoractivated receptor $\alpha$ agonists increase nitric oxide synthase expression in vascular endothelial cells," Arteriosclerosis, Thrombosis, and Vascular Biology, vol. 24, no. 4, pp. 658663, 2004.

[55] R. Brunmeir and F. Xu, "Functional regulation of PPARs through post-translational modifications," International Journal of Molecular Sciences, vol. 19, no. 6, p. 1738, 2018.

[56] I. Inoue, S. I. Goto, T. Matsunaga et al., "The ligands/activators for peroxisome proliferator-activated receptor $\alpha(\operatorname{PPAR} \alpha)$ and PPAR $\gamma$ increase $\mathrm{Cu}^{2+}, \mathrm{Zn}^{2+}$-superoxide dismutase and decrease $\mathrm{p} 22$ phox message expressions in primary endothelial cells," Metabolism, vol. 50, no. 1, pp. 3-11, 2001.

[57] A. Yu, R. Zhou, B. Xia, W. Dang, Z. Yang, and X. Chen, "NAMPT maintains mitochondria content via NRF2-PPAR$\alpha / \mathrm{AMPK} \alpha$ pathway to promote cell survival under oxidative stress," Cellular Signalling, vol. 66, p. 109496, 2020.

[58] K. M. Holmstrom, R. V. Kostov, and A. T. Dinkova-Kostova, "The multifaceted role of Nrf2 in mitochondrial function," Current Opinion in Toxicology, vol. 1, pp. 80-91, 2016.

[59] T. Li, L. Chen, Y. Yu, B. Yang, P. Li, and X. Q. Tan, "Resveratrol alleviates hypoxia/reoxygenation injury-induced mitochondrial oxidative stress in cardiomyocytes," Molecular Medicine Reports, vol. 19, no. 4, pp. 2774-2780, 2019.

[60] G. Ilangovan, S. Osinbowale, A. Bratasz et al., "Heat shock regulates the respiration of cardiac $\mathrm{H} 9 \mathrm{c} 2$ cells through upregulation of nitric oxide synthase," American Journal of Physiology. Cell Physiology, vol. 287, no. 5, pp. C1472-C1481, 2004.

[61] ACCORD Study Group, ACCORD Eye Study Group, E. Y. Chew et al., "Effects of medical therapies on retinopathy progression in type 2 diabetes," The New England Journal of Medicine, vol. 363, no. 3, pp. 233-244, 2010.

[62] D. C. Burgess, D. Hunt, L. Li et al., "Incidence and predictors of silent myocardial infarction in type 2 diabetes and the effect of fenofibrate: an analysis from the Fenofibrate Intervention and Event Lowering in Diabetes (FIELD) study," European Heart Journal, vol. 31, no. 1, pp. 92-99, 2010.
[63] C. Koopal, F. L. J. Visseren, J. Westerink, Y. van der Graaf, H. N. Ginsberg, and A. C. Keech, "Predicting the effect of fenofibrate on cardiovascular risk for individual patients with type 2 diabetes," Diabetes Care, vol. 41, no. 6, pp. 1244-1250, 2018.

[64] M. L. Morieri, H. S. Shah, J. Sjaarda et al., "PPARA polymorphism Influences the cardiovascular benefit of fenofibrate in type 2 diabetes: findings from ACCORD-Lipid," Diabetes, vol. 69, no. 4, pp. 771-783, 2020. 